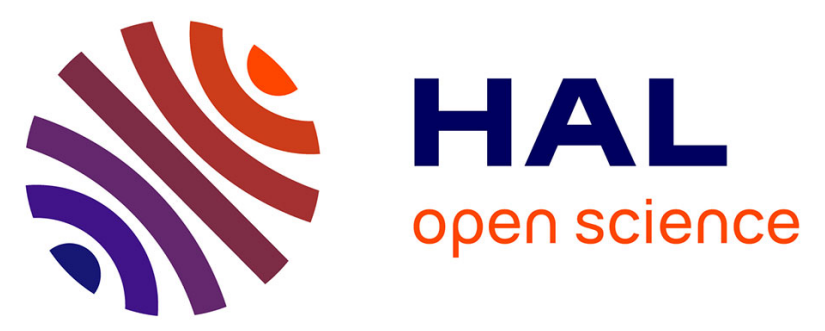

\title{
Rational Design of Dual IR and Visible Highly Luminescent Light-Lanthanides-Based Coordination Polymers
}

Youenn Pointel, Yan Suffren, Carole Daiguebonne, François Le Natur, Stéphane Freslon, Guillaume Calvez, Kevin Bernot, Olivier Guillou

\section{To cite this version:}

Youenn Pointel, Yan Suffren, Carole Daiguebonne, François Le Natur, Stéphane Freslon, et al.. Rational Design of Dual IR and Visible Highly Luminescent Light-Lanthanides-Based Coordination Polymers. Inorganic Chemistry, 2020, 59 (15), pp.10673-10687. 10.1021/acs.inorgchem.0c01136 . hal02901271

\section{HAL Id: hal-02901271 \\ https://hal.science/hal-02901271}

Submitted on 27 Aug 2020

HAL is a multi-disciplinary open access archive for the deposit and dissemination of scientific research documents, whether they are published or not. The documents may come from teaching and research institutions in France or abroad, or from public or private research centers.
L'archive ouverte pluridisciplinaire HAL, est destinée au dépôt et à la diffusion de documents scientifiques de niveau recherche, publiés ou non, émanant des établissements d'enseignement et de recherche français ou étrangers, des laboratoires publics ou privés. 


\section{Rational design of dual IR and visible highly luminescent light-lanthanides-based coordination polymers.}

Youenn Pointele ${ }^{\mathrm{a}, \mathrm{b}, \mathrm{c}}$, Yan Suffren ${ }^{\mathrm{a}, \mathrm{c}}$, Carole Daiguebonne ${ }^{\mathrm{a}, \mathrm{c}}$, François Le Natur ${ }^{\mathrm{b}, \mathrm{c}}$,

Stéphane Freslon ${ }^{\mathrm{a}, \mathrm{c}}$, Guillaume Calvez ${ }^{\mathrm{a}, \mathrm{c}}$, Kevin Bernot ${ }^{\mathrm{a}, \mathrm{c}}$ and Olivier Guillou ${ }^{\mathrm{a}, \mathrm{c}, *}$.

a Univ Rennes, INSA Rennes, CNRS UMR 6226 "Institut des Sciences Chimiques de Rennes", F-35708 Rennes, France.

${ }^{\mathrm{b}}$ Olnica, 40 Rue du Bignon, F-35135 Chantepie, France.

${ }^{c}$ ChemInTag, INSA Rennes, Olnica, CNRS, F-35708 Rennes, France.

* To whom correspondence should be addressed. 


\section{ABSTRACT.}

A series of isostructural homo- and hetero-lanthanide coordination polymers of formula $\left[\mathrm{Ln}_{2}(\mathrm{dcpa})_{3}\left(\mathrm{H}_{2} \mathrm{O}\right)\right]_{\infty}$ with $\mathrm{Ln}=\mathrm{La}-\mathrm{Gd}$ has been obtained by reactions in water between the lightest lanthanide chlorides and the di-sodium salt of 4,5-dichlorophthalic acid ( $\mathrm{H}_{2} \mathrm{dcpa}$ ). They present particularly high thermal stability for coordination compounds (up to $400{ }^{\circ} \mathrm{C}$ ). Their luminescent properties have been studied in details. Interestingly an insensitivity to water coordination as well as a very strong effect of optical dilution is observed. Therefore molecular alloys with very high lanthanum concentration have been prepared. Some of them present highly tunable and very intense luminescence. For examples, to the best of our knowledge, $\left[\mathrm{Sm}_{0.04} \mathrm{La}_{1.96}(\mathrm{dcpa})_{3}\left(\mathrm{H}_{2} \mathrm{O}\right)\right]_{\infty}$ presents one of the highest overall quantum yield measured so far for a $\mathrm{Sm}^{3+}$-based coordination compound $\left(\mathrm{Q}_{\mathrm{Sm}}^{\mathrm{Ligand}}=9.2 \%\right)$

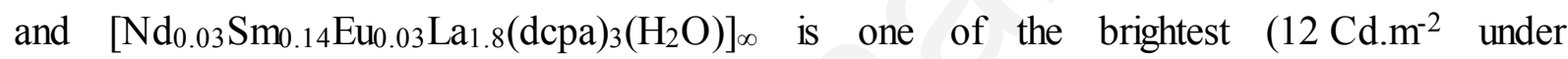
$0.75 \mathrm{~mW} . \mathrm{cm}^{-2}$ UV flux) multi-emissive visible and near infra-red lanthanide-coordination polymer reported to date. 


\section{INTRODUCTION.}

For more than a decade, lanthanide-based coordination polymers ${ }^{1}$ have attracted growing interest, in part because of their unique optical properties. ${ }^{2-9}$ Indeed, they can find their applications in various technological fields such as molecular sensing, ${ }^{10-15}$ light and display $^{6}, 16$ or fight against counterfeiting. ${ }^{17-20}$ Therefore, the quest of new lanthanide-based coordination polymers that exhibit original or more efficient luminescent properties is a particularly active field of research. ${ }^{21}$ In order to obtain efficient materials one has to judiciously choose the ligand ${ }^{22-26}$ and/or the metallic centers. ${ }^{27-29}$ As far as metallic centers are concerned, the synthesis of hetero-lanthanide-based compounds appears as a promising strategy. Indeed it has been demonstrated ${ }^{30}$ that, in this class of compounds, first described by Zhou et al. ${ }^{31}$ in 1994, lanthanide ions distribute randomly over the different metallic centers of the crystal structure so forming molecular alloys ${ }^{32}$ that allow modulation of the emission color and intensity. ${ }^{33-41}$ Of course, the choice of the ligand is also of first importance. Indeed, because of the shielded character of the $4 \mathrm{f}$ valence orbitals of the lanthanide ions, ${ }^{42}$ the ligand has deciding influence upon the crystal structure and upon the Ligand-to-Lanthanide energy transfers. ${ }^{43}$ Therefore, the quest for new ligands that can provide improved luminescent properties is a continuous concern..$^{20,38-39}$

As far as potential technological applications are targeted, ligands must be commercially available at low cost and thermally stable. Moreover the synthetic process used for the design of lanthanide-based coordination polymers must be as respectful of environment as possible. ${ }^{44}$

On the basis of these prerequisites, we have undertaken the study of lanthanide-based coordination polymers with 4,5-dichlorophthalate ligand (hereafter symbolized by dcpa ${ }^{2-}$ ) (Scheme 1). Indeed, it has previously been demonstrated that this ligand presents an excellent 
antenna effect ${ }^{45}$ toward lanthanide ions and leads to lanthanide-based coordination polymers that exhibit very intense luminescence. ${ }^{20}$<smiles>O=C(O)c1cc(Cl)c(Cl)cc1C(=O)O</smiles>

Scheme 1. Schematic representation of 4,5-dichlorophthalic acid hereafter referenced as $\mathrm{H}_{2}$ (dcpa).

Moreover, to the best of our knowledge, there are only a few examples in literature of lanthanide-based coordination polymers with this ligand, and most of them have been obtained by hydrothermal synthesis. ${ }^{20,}{ }^{46-47}$ In the frame of this study we have prepared, via an environment respectful synthetic process, a family of homo- and hetero-lanthanide-based coordination polymers with general chemical formula $\left[\mathrm{Ln}_{2}(\mathrm{dcpa})_{3}\left(\mathrm{H}_{2} \mathrm{O}\right)\right]_{\infty}$ with $\mathrm{Ln}=\mathrm{La}-\mathrm{Gd}$ (except Pm). These compounds are isostructural to $\left[\mathrm{Eu}_{2}(\mathrm{dcpa})_{3}\left(\mathrm{H}_{2} \mathrm{O}\right)\right]_{\infty},{ }^{46}$ that has been previously reported. As anticipated, some of them present excellent luminescence properties.

\section{EXPERIMENTAL SECTION}

Lanthanide oxides (4N) were purchased from AMPERE Company and used without further purification. Lanthanide chlorides were prepared according to literature. ${ }^{48}$ 4,5-dichlorophthalic acid was purchased from Clinisciences Company and used without further purification. Its sodium salt was prepared as previously described. ${ }^{20}$ 


\section{Synthes is of the homo-lanthanide-based coordination polymers.}

An aqueous solution of a lanthanide chloride $(0.5 \mathrm{mmol}$ in $5 \mathrm{~mL})$ and an aqueous solution of the sodium salt of 4,5-dichlorophthalic acid $(0.75 \mathrm{mmol}$ in $5 \mathrm{~mL})$ were mixed and stirred for $30 \mathrm{~min}$ at room-temperature. Precipitation occurred. The solid was filtered, rinsed with water and dried at ambient temperature and pressure. All IR spectra were similar and show the characteristic peaks of carboxylate function $\left(1386 \mathrm{~cm}^{-1}\right.$ and $\left.1560 \mathrm{~cm}^{-1}\right)$. As a matter of example, IR spectrum of $\left[\mathrm{Nd}_{2}(\mathrm{dcpa})_{3}\left(\mathrm{H}_{2} \mathrm{O}\right)\right]_{\infty}$ is reported in Figure S1. Iso-structurality of the compounds with $\left[\mathrm{Eu}_{2}(\mathrm{dcpa})_{3}\left(\mathrm{H}_{2} \mathrm{O}\right)\right]_{\infty}$ was assumed on the basis of their X-ray powder diffraction patterns (Figure S2).

\section{Synthesis of the hetero-lanthanide-based coordination polymers.}

Hetero-lanthanide coordination polymers have been prepared according to the procedure described above for homo-lanthanide compounds, simply replacing the lanthanide chloride solution by a solution of the appropriate mixture of lanthanide chlorides. Iso-structurality of these compounds with $\left[\mathrm{Eu}_{2}(\mathrm{dcpa})_{3}\left(\mathrm{H}_{2} \mathrm{O}\right)\right]_{\infty}$ has been assumed on the basis of their X-ray powder diffraction diagrams (Figures S3-S14). Experimental lanthanides contents were determined by EDS measurements (Tables S1-S12). Random distribution of the different metallic ions over the metallic sites of the crystal structure has been assumed on the basis of previously reported results obtained on similar compounds. ${ }^{28,30,49-50}$

\section{X-ray powder diffraction diagrams.}

All X-ray powder diffraction diagrams have been collected with a Panalytical X'Pert Pro diffractometer equipped with an $\mathrm{X}^{\prime}$ Celerator detector. Experimental conditions are: $\mathrm{CuK} \alpha$ radiation $(\lambda=1.542 \AA), \mathrm{I}=40 \mathrm{~mA}, \mathrm{~V}=45 \mathrm{kV}, \theta / \theta$ mode. Thermo-dependent $\mathrm{X}$-ray powder diffraction diagrams have been collected with the same apparatus, equipped with an 
Anton Parr HTK 1200 furnace, in the same experimental conditions, between room-temperature and $1000{ }^{\circ} \mathrm{C}$ under $\mathrm{N}_{2}$ flux. Simulated, from the crystal structure, X-ray diffraction diagram has been calculated using PowderCell and WinPlotR programs. ${ }^{51-52}$ Fit of the experimental $\left[\mathrm{Eu}_{2}(\mathrm{dcpa})_{3}\left(\mathrm{H}_{2} \mathrm{O}\right)\right]_{\infty}$ powder diffraction diagram has been performed using the Fullprof suite ${ }^{53}$ by Le Bail method ${ }^{54}$ (Figure S15).

\section{Electronic microscopy and Energy Dispersive Spectroscopy (EDS).}

EDS measurements have been performed with a Hitachi TM-1000, Tabletop Microscope version 02.11 (Hitachi High-Technologies, Corporation Tokyo Japan) with EDS analysis system (SwiftED-TM, Oxford Instruments Link INCA). Samples were assembled on carbon discs, stuck on a carbon stub. Reproducibility of the elemental analyses has been checked by repeating the measurements several times for several spots per sample. These experiments support the homogeneity of the samples.

\section{Thermal analyses.}

Thermal analyses have been performed with a Perkin Elmer Pyris Diamond TGA/TDA analyzer between room-temperature and $950{ }^{\circ} \mathrm{C}$ with a $5{ }^{\circ} \mathrm{C} \cdot \mathrm{min}^{-1}$ rate in platinum crucibles under $\mathrm{N}_{2}$ atmosphere. The compound was maintained for $1 \mathrm{~h}$ at $950{ }^{\circ} \mathrm{C}$ under air atmosphere in order to insure complete combustion.

\section{Optical measurements.}

Solid-state emission and excitation spectra have been measured on a Horiba Jobin-Yvon Fluorolog III fluorescence spectrometer equipped with a Xe lamp $450 \mathrm{~W}$, a UV-Vis photomultiplier (Hamamatsu R928, sensitivity $190-860 \mathrm{~nm}$ ) and an IR-photodiode cooled by liquid nitrogen (InGaAs, sensitivity $800-1600 \mathrm{~nm}$ ). Quantum yield measurements 
were performed using a F-3018 Jobin-Yvon integrating sphere $\left(\Phi=\left(E_{c}-E_{a}\right) /\left(L_{a}-L_{c}\right)\right.$ where $E_{c}$ is the integrated emission spectrum of the sample, $E_{a}$ the integrated "blank" emission spectrum, $\mathrm{L}_{\mathrm{a}}$ the "blank" absorption and $\mathrm{L}_{\mathrm{c}}$ the sample absorption at the excitation wavelength). The emission/excitation spectra and quantum yield recordings were realized on powder samples introduced in cylindrical quartz cells of $0.7 \mathrm{~cm}$ diameter and $2.4 \mathrm{~cm}$ height, which were placed directly inside the integrating sphere, or on powder samples pasted on copper plates with silver glue. The luminescence of the La-based microcrystalline powders placed in quartz capillary tubes has been measured at $77 \mathrm{~K}$ (Dewar + liquid nitrogen). For the measurements realized at variable temperature $(77 \mathrm{~K}-300 \mathrm{~K})$, the samples were introduced in an OptistatCF liquid nitrogen cooled cryostat from Oxford Instruments. Longest luminescence decays $(\tau>10 \mu \mathrm{s})$ have also been measured at room-temperature using this apparatus with a Xenon flash lamp (phosphorescence mode). Shortest luminescence decays $(\tau<10 \mu \mathrm{s})$ were measured directly with the fluorescence spectrometer coupled with an additional TCSPC module (Time-Correlated-Single-Photon-Counting) and a $300 \mathrm{~nm}$ pulsed Delta-Diode. Lifetimes and quantum yields are averages of three independent determinations.

Comparative solid-state luminescent spectra have been measured on the same fluorimeter on powders samples shaped into pellets $\left(1.5 \mathrm{~cm}^{2}\right)$. Spectra were recorded between 450 and $1500 \mathrm{~nm}$ with the two detectors (PMT and photo-diode) under identical operating conditions and without turning the lamp off to ensure a valid comparison between the emission spectra.

Appropriate filters were used to remove the residual excitation laser light, the Rayleigh scattered light and associated harmonics from spectra. All spectra were corrected for the instrumental response function.

Solid-state UV-visible absorption measurements have been performed with a Perkin Elmer Lambda 650 spectrometer equipped with a $60 \mathrm{~mm}$ integrated sphere. 
IR spectra have been recorded with a Perkin Elmer Frontier FT-IR spectrometer equipped with a UATR accessory (Universal Attenuated Total Reflectance) between 650 and $4000 \mathrm{~cm}^{-1}$.

Luminance of the samples expressed in $\mathrm{Cd}^{-2} \mathrm{~m}^{-2}$ have been measured with a Gigahertz-Optik X1-1 optometer with an integration time of $200 \mathrm{~ms}$ on $1.5 \mathrm{~cm}^{2}$ pellets under UV irradiation $\left(\lambda_{\mathrm{exc}}=312 \mathrm{~nm}\right)$. The intensity of the UV flux at sample location, $0.75(2) \mathrm{mW} . \mathrm{cm}^{-2}$, has been measured with a VilberLourmat VLX-3W radiometer. $\left[\mathrm{Tb}_{2}(\mathrm{bdc})_{3} \cdot 4 \mathrm{H}_{2} \mathrm{O}\right]_{\infty}$, where $\mathrm{bdc}^{2-}$ stands for terephthalate, was used as a standard. Its luminance is $142(2) \mathrm{Cd}_{\mathrm{m}} \mathrm{m}^{-2}$ under these operating conditions $\left(\lambda_{\mathrm{exc}}=312 \mathrm{~nm}\right.$; flux $\left.=0.75(2) \mathrm{mW} \cdot \mathrm{cm}^{-2}\right) \cdot{ }^{30}$

The CIE (Commission Internationale de l'Eclairage) (x, y) emission color coordinates $^{55-56}$ were measured with a MSU-003 colorimeter (Majantys) equipped with the PhotonProbe 1.6.0 Software (Majantys). Color measurements: $2^{\circ}$, CIE 1931, step $5 \mathrm{~nm}$, under $312 \mathrm{~nm} \quad \mathrm{UV} \quad$ light. $\mathrm{X}=k \times \int_{380 \mathrm{~nm}}^{780 \mathrm{~nm}} I_{\lambda} \times x_{\lambda}, \quad \mathrm{Y}=k \times \int_{380 \mathrm{~nm}}^{780 \mathrm{~nm}} I_{\lambda} \times y_{\lambda} \quad$ and $\quad \mathrm{Z}=k \times$ $\int_{380 \mathrm{~nm}}^{780 \mathrm{~nm}} I_{\lambda} \times z_{\lambda}$ with $\mathrm{k}$ constant for the measurement system, $\mathrm{I}_{\lambda}$ sample spectrum intensity wavelength depending, $\mathrm{x}_{\lambda}, \mathrm{y}_{\lambda}, \mathrm{z}_{\lambda}$ trichromatic values $\mathrm{x}=\mathrm{X} /(\mathrm{X}+\mathrm{Y}+\mathrm{Z}), \mathrm{y}=\mathrm{Y} /(\mathrm{X}+\mathrm{Y}+\mathrm{Z})$ and $\mathrm{z}=\mathrm{Z} /(\mathrm{X}+\mathrm{Y}+\mathrm{Z})$. Mean $\mathrm{xyz}$ values are given for each sample, which act as light sources (luminescent samples). Standards from Phosphor Technology used, calibrated at $312 \mathrm{~nm}$ : red phosphor $\mathrm{Gd}_{2} \mathrm{O}_{2} \mathrm{~S}: \mathrm{Eu}(\mathrm{x}=0.667, \mathrm{y}=0.330)$ and green phosphor $\mathrm{Gd}_{2} \mathrm{O}_{2} \mathrm{~S}: \mathrm{Tb} \quad(\mathrm{x}=0.328$, $\mathrm{y}=0.537)$ 


\section{RESULTS AND DISCUSSION.}

Crystal structure and thermal behavior of $\left[\operatorname{Ln}_{2}(d c p a)_{3}\left(\mathrm{H}_{2} \mathrm{O}\right)\right]_{\infty}$ with $\mathrm{Ln}=\mathrm{La}-\mathrm{Gd}($ except Pm).

Reactions in water, at room-temperature, between lanthanide chlorides and the di-sodium salt of 4,5-dichlorophthalic acid, lead to microcrystalline precipitates. All the obtained compounds reveal to be iso-structural to $\left[\mathrm{Eu}_{2}(\mathrm{dcpa})_{3}\left(\mathrm{H}_{2} \mathrm{O}\right)\right]_{\infty}$ that has been structurally described previously (CCDC-1551529). ${ }^{46}$ Therefore only a brief structural description, that is necessary for luminescence properties understanding, is given below. This coordination polymer crystallizes in the monoclinic system, space group $P 2_{1} / c\left(N^{\circ} 14\right)$. There are two crystallographically independent $\mathrm{Eu}^{3+}$ ions in the crystal structure. Eul is eight coordinated by seven oxygen atoms from carboxylate functions that belong to five different ligands and one oxygen atom from a coordination water molecule, that form a slightly distorted trigonal dodecahedron. Eu2 is nine coordinated by oxygen atoms from nine carboxylate functions that belong to six different ligands that form a slightly distorted capped square antiprism (Figure 1). It can be noticed that, in this compound, there is no crystallization water molecule and only one coordination water molecule per formula unit. This low hydration rate is confirmed by thermal analyses. There are three independent $\mathrm{dcpa}^{2-}$ ligands in the crystal structure. Their coordination modes are drawn in Figure 1. This figure shows that all the three ligands are polydentate and bind three to four lanthanide ions. 


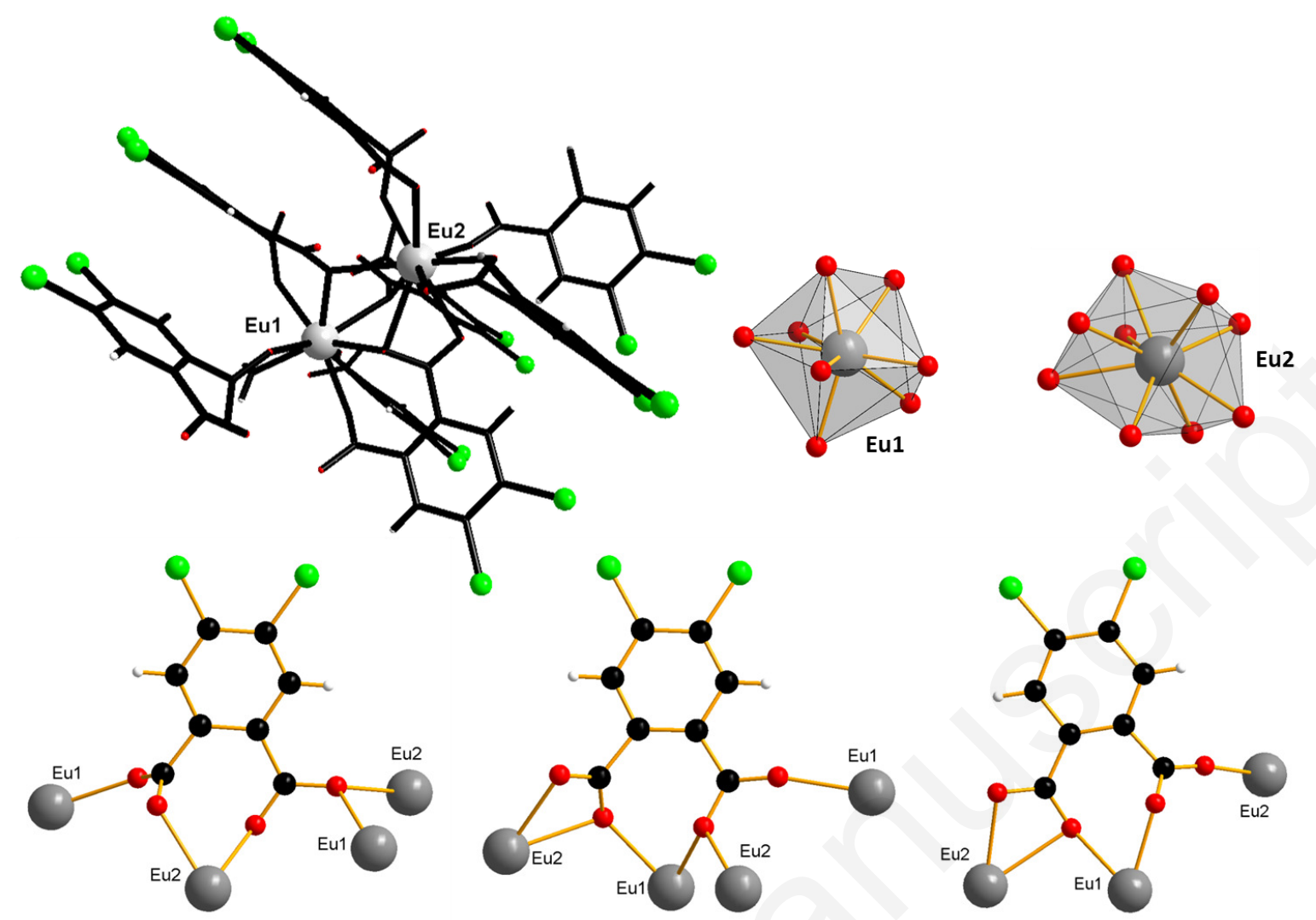

Figure 1. Projection view of an extended asymmetric unit of $\left[\mathrm{Eu}_{2}(\mathrm{dcpa})_{3} \cdot \mathrm{H}_{2} \mathrm{O}\right]_{\infty}$ (top left); $\mathrm{Eu}^{3+}$ ions polyhedrons (top right). Coordination modes of the $\mathrm{dcpa}^{2-}$ ligands (bottom). Redrawn from reference 46.

The crystal structure can be described on the basis of inorganic chains made of dimeric Eu1-Eu2 units that spread along the $c$-axis. Inside the dimeric units, the two lanthanide ions coordination polyhedrons share a face $\left(\mathrm{d}_{\mathrm{Eu}-\mathrm{Eu}}=3.8290(4) \AA\right)$ and coordination polyhedrons of adjacent lanthanide ions that belong to different dimeric units share a vertex $\left(\mathrm{d}_{\mathrm{Eu}-\mathrm{Eu}}=4.2132(2) \AA\right)$ (Figure 2). These inorganic chains are bound to each other by bridging $\mathrm{dcpa}^{2-}$ ligands so forming a 2D molecular framework. Shortest distances between lanthanide ions that belong to different inorganic chains lay in the range 5.3093(3)-9.0400(5) $\AA$ (Figure 2). All the chloride atoms point toward the inter-plane space (Figure 2) and insure the stability of the crystal packing by strong halogen-bonds $\left(\mathrm{d}_{\mathrm{Cl}-\mathrm{Cl}} \approx 3.3-3.7 \AA\right)$. Shortest inter-metallic distances between lanthanide ions that belong to different molecular layers are about $14-15 \AA$ that is greater than $10 \AA$ which is commonly considered as the threshold above which inter-metallic energy transfer mechanisms become less efficient. ${ }^{22,} 43$ 

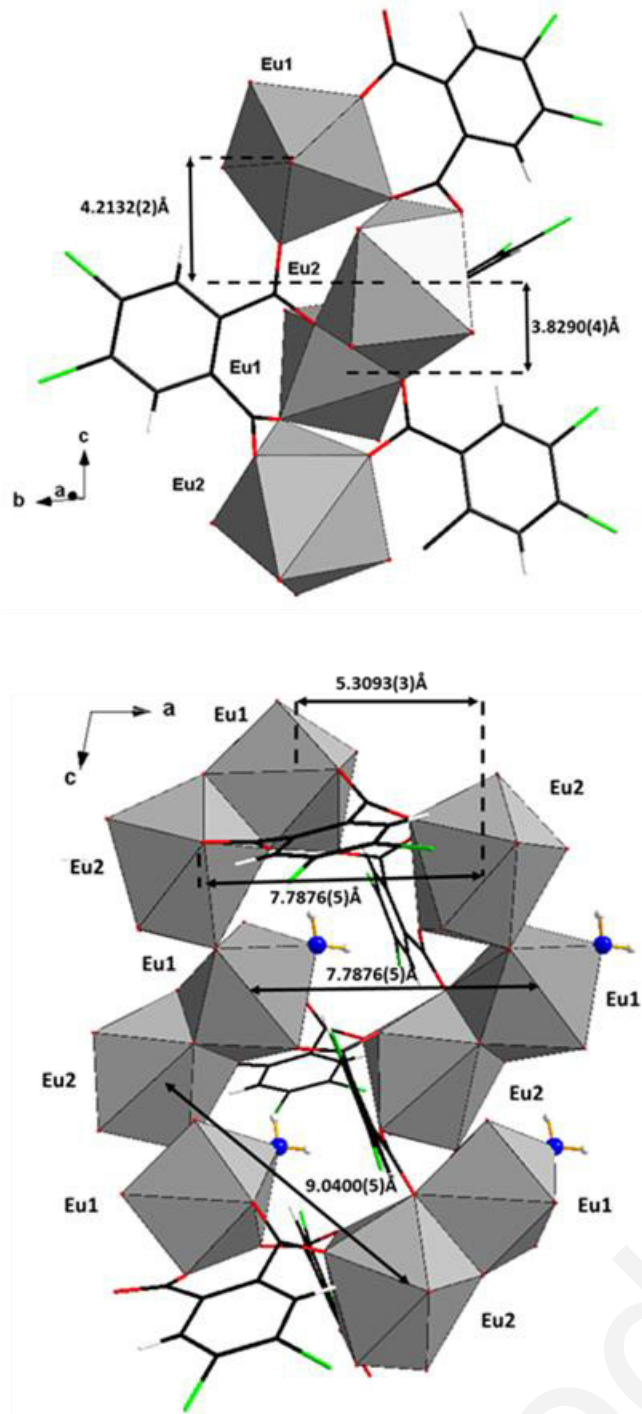

Figure 2. Left: Projection views of an inorganic chain (top left) and of two adjacent inorganic chains (bottom left). Lanthanide polyhedrons are drawn. Only relevant binding ligands are drawn. Characteristic inter-metallic distances are reported. Oxygen atoms of the coordination water molecules are in blue. Right: perspective view of an extended unit cell. Green balls symbolize chloride atoms. Redrawn from reference 46 .

From a global point of view, there are 13 lanthanide ions closer than $10 \AA$ from a given lanthanide ion. All of them belong to the same molecular layer (Scheme 2). 


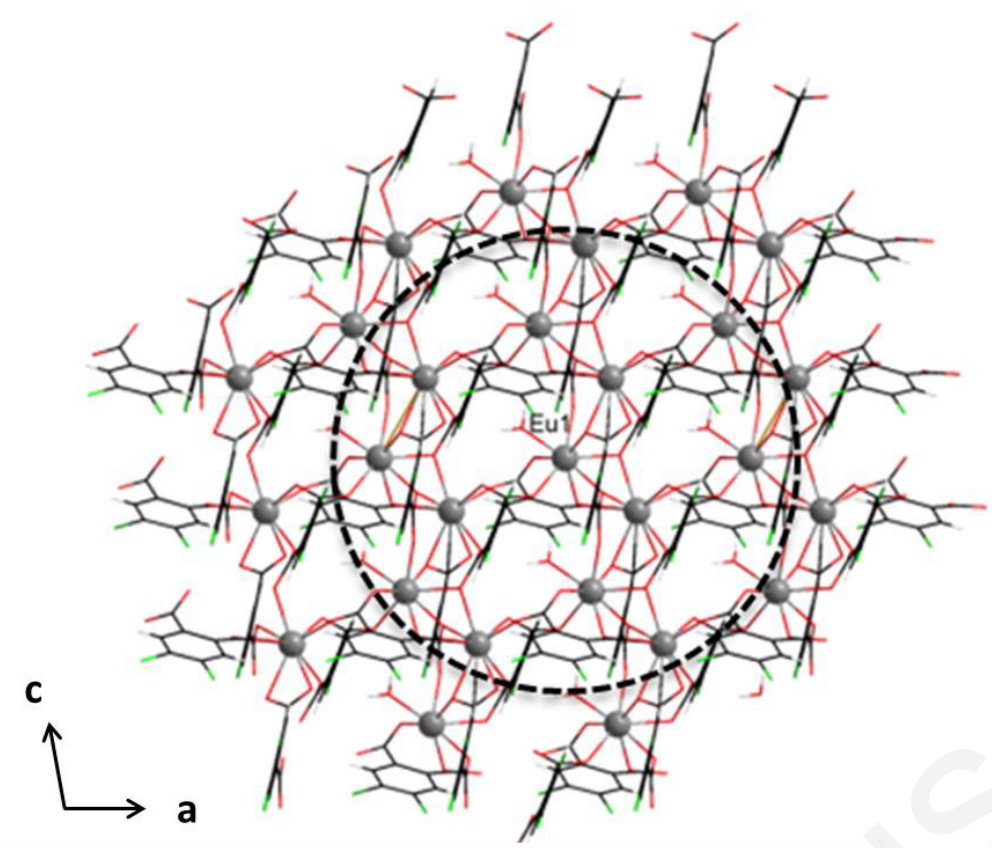

Scheme 2. Projection view along the $b$-axis of a molecular layer. Broken-line circle represents a $10 \AA$ distance from the central Eul atom. Redrawn from reference 46. The situation is identical for $\mathrm{Eu} 2$ as a central atom.

Thermal analysis under $\mathrm{N}_{2}$ flux of $\left[\mathrm{Sm}_{2}(\mathrm{dcpa})_{3}\left(\mathrm{H}_{2} \mathrm{O}\right)\right]_{\infty}$ (Figure 3) shows the departure of one water molecule around $100{ }^{\circ} \mathrm{C}(1.8 \%$-Calc. $2.0 \%)$. The resulting anhydrous compound remains unchanged until $400{ }^{\circ} \mathrm{C}$. Then, the ligands decompose leading to $\mathrm{Sm}_{2} \mathrm{O}_{3}$. Thermo-dependent powder X-ray diffraction diagrams have been collected (Figure 3): the crystal structure of the starting compound and that of the anhydrous phase are identical. This is quite rare in lanthanide coordination chemistry. In fact, because of the high structural versatility of lanthanide ions, a change in the hydration rate provokes, usually, a change in the crystal structure. ${ }^{57}$ In the present case, the carboxylate functions are overcrowded which prevents structural reorganization. The robustness of this crystal structure can be related to the strength of the molecular layers induced by the polydentate ligand and to the high density of halogen-bonds between them. It must also be noticed that de-hydrated sample does not re-hydrate when exposed to wet atmosphere. 

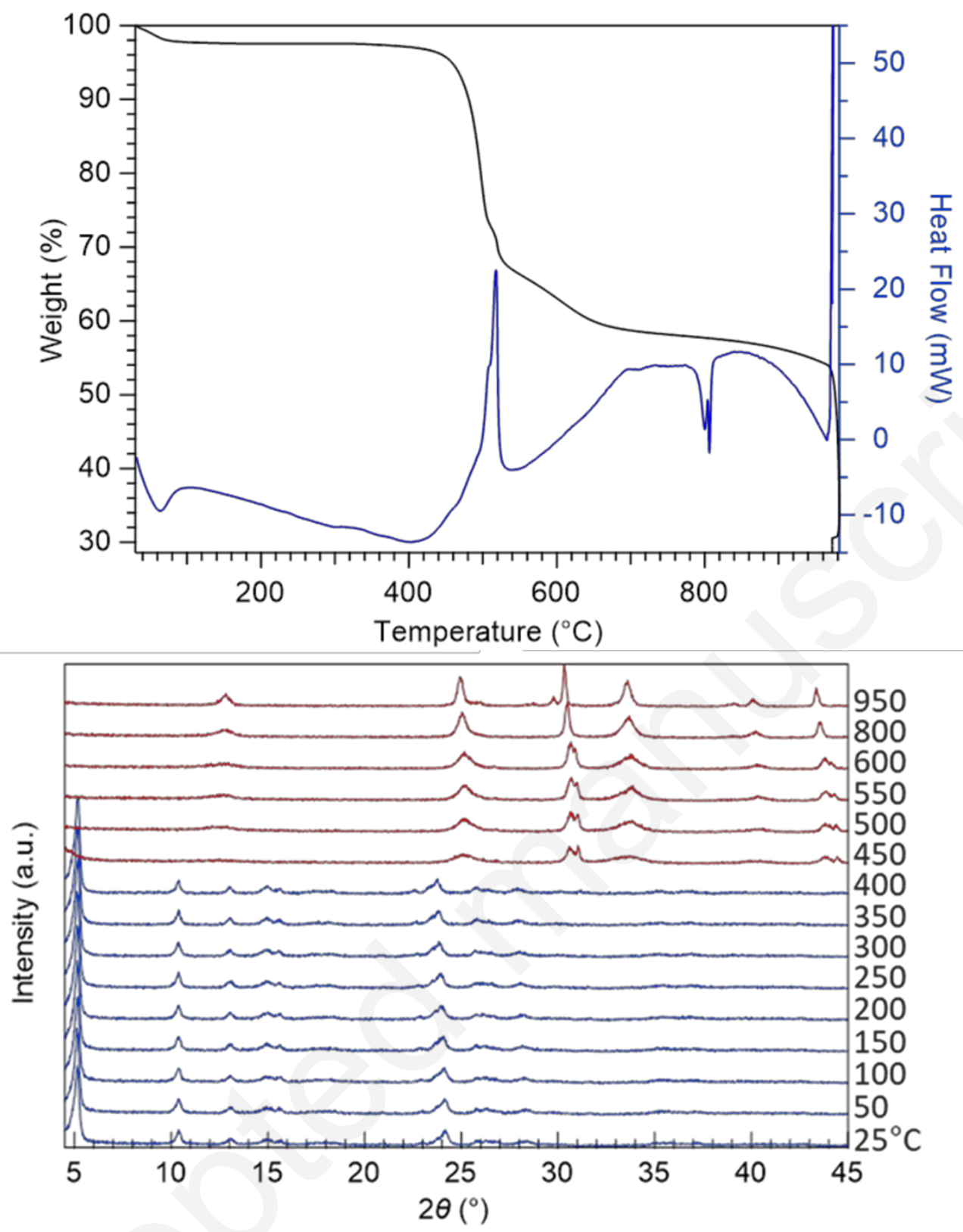

Figure 3. Top: Thermal analyses of $\left[\mathrm{Sm}_{2}(\mathrm{dcpa})_{3}\left(\mathrm{H}_{2} \mathrm{O}\right)\right]_{\infty}$. Bottom: Thermo-dependent X-ray diffraction patterns of $\left[\mathrm{Sm}_{2}(\mathrm{dcpa})_{3}\left(\mathrm{H}_{2} \mathrm{O}\right)\right]_{\infty}$ between $25^{\circ} \mathrm{C}$ and $950{ }^{\circ} \mathrm{C}$.

This quite high thermal stability, for a coordination compound, makes this series of compounds potentially interesting candidates for technological applications and encouraged us to deeply study their luminescent properties.

Luminescent properties of $\left[\operatorname{Ln}_{2}(\text { dcpa })_{3}\left(\mathrm{H}_{2} \mathrm{O}\right)\right]_{\infty}$ with $\mathrm{Ln}=\mathrm{La}-\mathrm{Gd}($ except Pm).

$\left[\mathrm{La}_{2}(\mathrm{dcpa})_{3}\left(\mathrm{H}_{2} \mathrm{O}\right)\right]_{\infty}$ 
Location of the first excited singlet and triplet state of the ligand are of first interest. We have estimated them by referring to the UV-vis absorption edge $\left(325 \mathrm{~nm} \approx 30800 \mathrm{~cm}^{-1}\right)$ and to the shortest wavelength of the phosphorescence band at $77 \mathrm{~K}\left(405 \mathrm{~nm} \approx 24700 \mathrm{~cm}^{-1}\right)$ of $\left[\mathrm{La}_{2}(\mathrm{dcpa})_{3}\left(\mathrm{H}_{2} \mathrm{O}\right)\right]_{\infty}$, respectively (Figures $\mathrm{S} 16$ and $\left.\mathrm{S} 17\right) .{ }^{43}$ According to Reinhoudt's empirical rules, ${ }^{58}$ inter-system crossing mechanism is efficient when the gap between the first excited triplet and singlet states is greater than $5000 \mathrm{~cm}^{-1}$. In the present case, the gap is about $6100 \mathrm{~cm}^{-1}$ and therefore Ligand-to-Lanthanide ion energy transfer is supposed to involve the excited triplet state of the ligand. It can also be noticed that the observed luminescent lifetime of $\left[\mathrm{La}_{2}(\mathrm{dcpa})_{3}\left(\mathrm{H}_{2} \mathrm{O}\right)\right]_{\infty}$ is very long $(124(1) \mathrm{ms})$ and much greater than what is usually observed for lanthanide-based coordination polymers. ${ }^{20,} 30$

\section{$\left[\mathrm{Eu}_{2}(\mathrm{dcpa})_{3}\left(\mathrm{H}_{2} \mathrm{O}\right)\right]_{\infty}$}

Among the homo-lanthanide compounds that constitute this family, the most promising one, as far as luminescence in the visible domain is targeted, is the Eu-based one. Its excitation and emission spectra have been recorded at room-temperature (Figure 4). Excitation spectrum shows a broad band centered at $303 \mathrm{~nm}$ that can be attributed to ligand ${ }^{1} \pi \rightarrow{ }^{1} \pi^{* / 3} \pi^{*}$ transitions and evidences an efficient antenna effect ${ }^{45}$ of the ligand for the Eu-derivative. It also shows excitation peaks that correspond to ${ }^{7} \mathrm{~F}_{0} \rightarrow{ }^{5} \mathrm{D}_{1-4}$ and ${ }^{7} \mathrm{~F}_{0} \rightarrow{ }^{5} \mathrm{~L}_{6-7}$ 4f-4f transitions. Room-temperature solid-state emission spectra have been recorded under $303 \mathrm{~nm}$ and $393.5 \mathrm{~nm}$ excitation wavelengths that correspond to the ${ }^{1} \pi \rightarrow{ }^{1} \pi * \beta \pi *$ ligand transition and to the ${ }^{7} \mathrm{~F}_{0} \rightarrow{ }^{5} \mathrm{~L}_{6} \mathrm{Eu}^{3+}$ transition, respectively. 


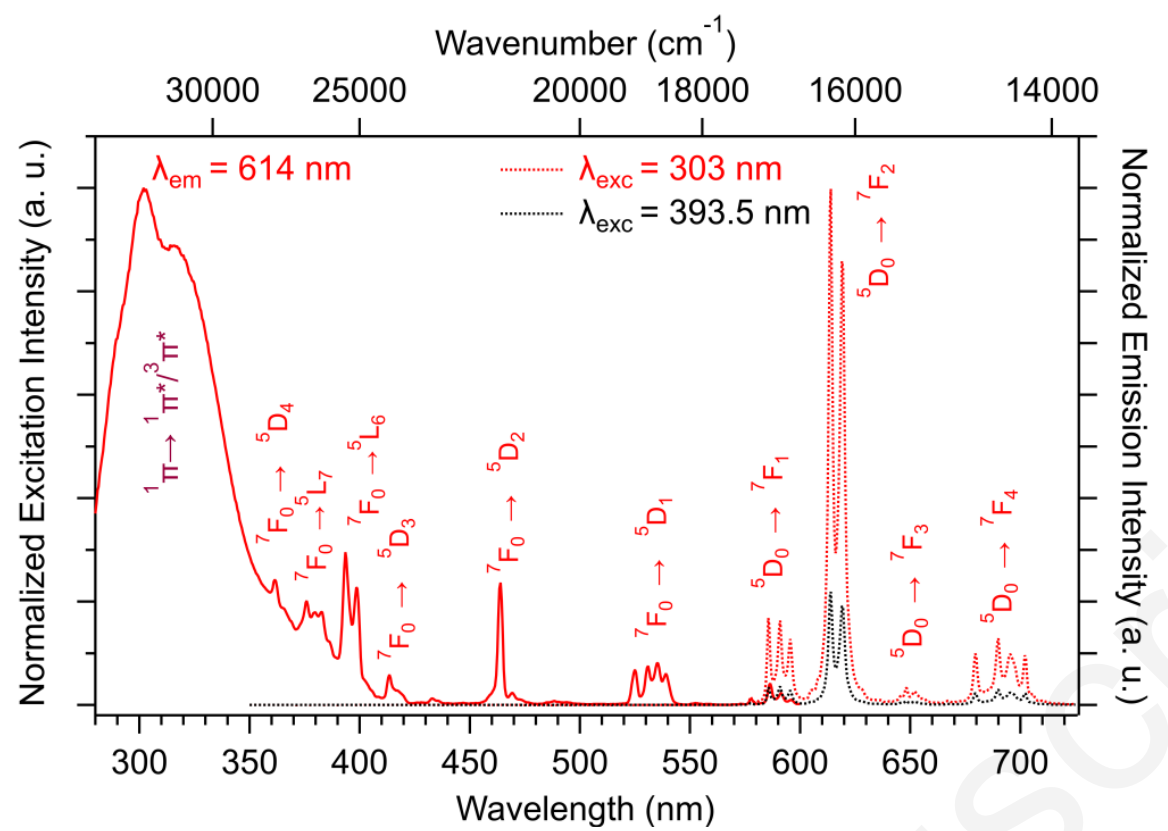

Figure 4. Room-temperature solid-state excitation $\left(\lambda_{\mathrm{em}}=614 \mathrm{~nm}\right.$, red curve) and emission spectra $\left(\lambda_{\text {exc }}=303 \mathrm{~nm}\right.$ and $\lambda_{\text {exc }}=393.5 \mathrm{~nm}$, red and black dotted curves, respectively) of $\left[\mathrm{Eu}_{2}(\mathrm{dcpa})_{3}\left(\mathrm{H}_{2} \mathrm{O}\right)\right]_{\infty}$.

Emission spectrum shows ${ }^{5} \mathrm{D}_{0} \rightarrow{ }^{7} \mathrm{~F}_{1-4}$ characteristic transitions of $\mathrm{Eu}^{3+}$ ions. ${ }^{59}$ It is dominated by the ${ }^{5} \mathrm{D}_{0} \rightarrow{ }^{7} \mathrm{~F}_{2}$ transition $(614 \mathrm{~nm})$. Actually, $\left[\mathrm{Eu}_{2}(\mathrm{dcpa})_{3}\left(\mathrm{H}_{2} \mathrm{O}\right)\right]_{\infty}$ exhibits bright red luminescence (luminance is $51(3) \mathrm{Cd} \cdot \mathrm{m}^{-2}$ under a $0.75(2) \mathrm{mW} \cdot \mathrm{cm}^{-2}$ luminous flux at $312 \mathrm{~nm})$. Overall quantum yield is $\mathrm{Q}_{\mathrm{Eu}}^{\mathrm{Ligand}}=28(3) \%$ and luminescence lifetime is $\tau_{\mathrm{obs}}=1.42(1) \mathrm{ms}$. This sizeable overall quantum yield is in agreement with empirical Latva's rules $^{60}$ that predict that such a first excited triplet state energy $\left(24700 \mathrm{~cm}^{-1}\right)$ favors efficient Ligand-to-Metal energy transfers without significant back-transfers.

Sensitization efficiency $\left(\eta_{\text {sens }}\right)$ that corresponds to the efficacy of the Ligand-to-Metal energy transfers, can be estimated, by the following empirical relationship

$$
Q_{\mathrm{Ln}}^{\text {Ligand }}=\eta_{\text {sens }} Q_{\mathrm{Ln}}^{\mathrm{Ln}}=\eta_{\text {sens }} \frac{\tau_{\text {obs }}}{\tau_{\text {rad }}}
$$

where $\mathrm{Q}_{\mathrm{Ln}}^{\mathrm{Ln}}$ is the intrinsic quantum yield upon direct excitation of the lanthanide ion and $\tau_{\mathrm{rad}}$ is the radiative lifetime. ${ }^{61-62}$ For Eu-containing compounds, a simplified relationship allows the estimation of the radiative lifetime $:^{63}$ 


$$
\frac{1}{\tau_{\mathrm{rad}}}=\mathrm{A}_{\mathrm{MD}, 0} \mathrm{n}^{3}\left(\frac{\mathrm{I}_{\mathrm{tot}}}{\mathrm{I}_{\mathrm{MD}}}\right)
$$

where $\mathrm{A}_{\mathrm{MD}, 0}$ is equal to $14.65 \mathrm{~s}^{-1}$ and corresponds to the spontaneous emission probability of the magnetic dipole ${ }^{5} \mathrm{D}_{0} \rightarrow{ }^{7} \mathrm{~F}_{1}, \mathrm{n}$ is the refractive index and $\mathrm{I}_{\text {tot }}$ and $\mathrm{I}_{\mathrm{MD}}$ are the integrated intensities of the ${ }^{5} \mathrm{D}_{0} \rightarrow{ }^{7} \mathrm{~F}_{\mathrm{J}} \quad(\mathrm{J}=0-6)$ transitions and of the ${ }^{5} \mathrm{D}_{0} \rightarrow{ }^{7} \mathrm{~F}_{1}$ transition only, respectively. Refractive index $\mathrm{n}$ was estimated to 1.50 on the basis of known refractive indexes of similar compounds. ${ }^{25}, 30$ With these assumptions, one obtains $\tau_{\mathrm{rad}}=2.7(1) \mathrm{ms}$ and $\mathrm{Q}_{\mathrm{Ln}}^{\mathrm{Ln}}=53(2) \%$ which means that $\eta_{\text {sens }}$ is close to $53 \%$. Energy transfer mechanisms that govern the luminescence of $\left[\mathrm{Eu}_{2}(\mathrm{dcpa})_{3}\left(\mathrm{H}_{2} \mathrm{O}\right)\right]_{\infty}$ are reported on Scheme 3.

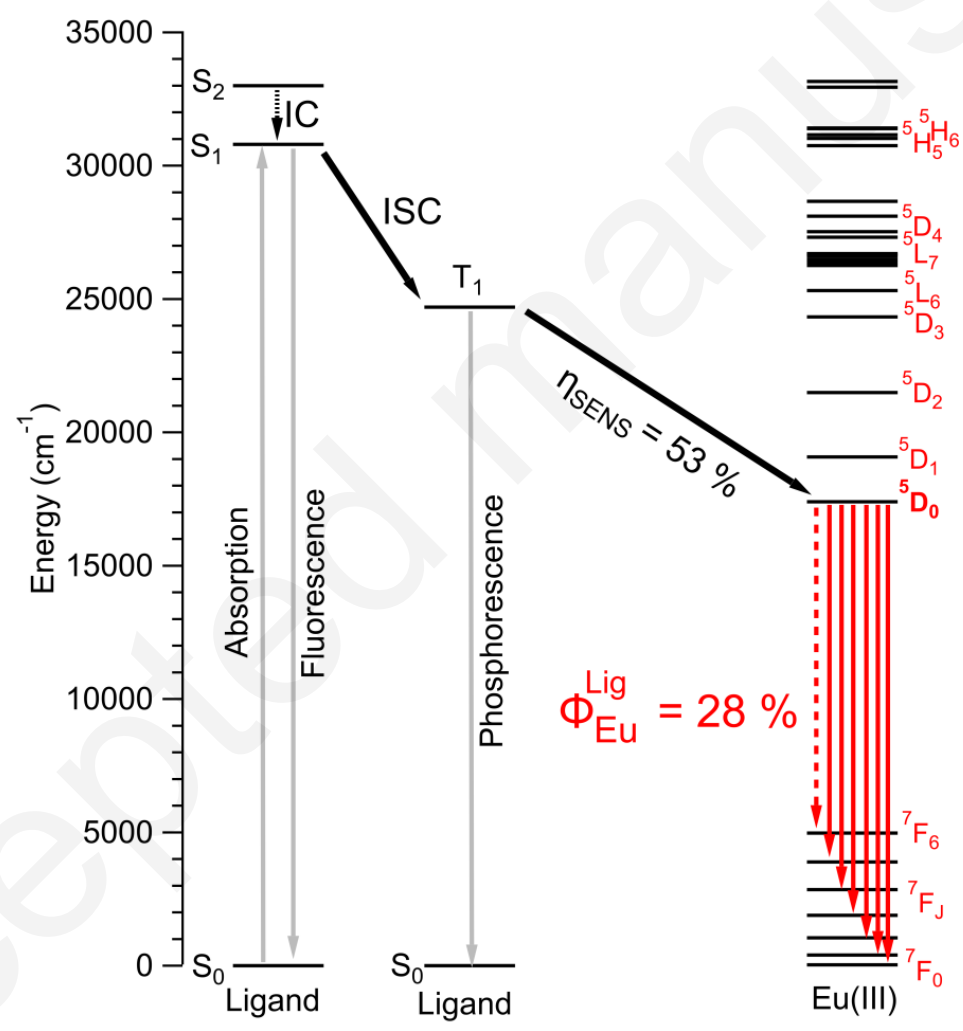

Scheme 3. Schematic representation of the energy transfer mechanisms that govern $\left[\mathrm{Eu}_{2}(\mathrm{dcpa})_{3}\left(\mathrm{H}_{2} \mathrm{O}\right)\right]_{\infty}$. The red arrows are the emission in both the visible and the IR (broken arrow) domains. IC, ISC and $\eta$ SENS stand for Internal Conversion, Inter-Crossing-System and Sensitization Energy processes, respectively. S and Tstand for Singlet and Triplet states, respectively.

The sizeable overall quantum yield $\left(Q_{E u}^{\text {Ligand }}=28(3) \%\right)$ associated with a quite moderate sensitization efficiency $\left(\eta_{\text {sens }}=53 \%\right)$ and a quite high intrinsic quantum yield 
$\left(\mathrm{Q}_{\mathrm{Eu}}^{\mathrm{Eu}}=53(2) \%\right)^{30,64}$ strongly suggest that non-radiative de-excitation due to $\mathrm{O}-\mathrm{H}$ vibrators is weak. Indeed, there is only one coordination water molecule per formula unit in this compound. In order to confirm that it contributes weakly to non-radiative de-excitation we have measured, at room-temperature, excitation and emission spectra of a dehydrated sample of $\left[\mathrm{Eu}_{2}(\mathrm{dcpa})_{3}\right]_{\infty}$ (obtained after heating $\left[\mathrm{Eu}_{2}(\mathrm{dcpa})_{3}\left(\mathrm{H}_{2} \mathrm{O}\right)\right]_{\infty}$ in a furnace at $200{ }^{\circ} \mathrm{C}$, under $\mathrm{N}_{2}$ atmosphere, for 2 hours) (Figure S18). Figure S18 shows that both hydrated and de-hydrated compounds exhibit similar luminescent behaviors. Moreover luminescence lifetimes and overall quantum yields are identical. This confirms that non-radiative de-excitation due to $\mathrm{O}-\mathrm{H}$ vibrators is negligible. This constitutes an asset as far as technological applications are targeted because the user has not to take care of the hydration rate of the compound during the industrial process. This feature is very rare for rare-earth coordination polymers.

Because hydration rate has negligible influence on luminescence properties, only hydrated phases are studied in the following.

\section{$\left[\mathrm{Sm}_{2}(\mathrm{dcpa})_{3}\left(\mathrm{H}_{2} \mathrm{O}\right)\right]_{\infty},\left[\operatorname{Pr}_{2}(\mathrm{dcpa})_{3}\left(\mathrm{H}_{2} \mathrm{O}\right)\right]_{\infty}$ and $\left[\mathrm{Nd}_{2}(\mathrm{dcpa})_{3}\left(\mathrm{H}_{2} \mathrm{O}\right)\right]_{\infty}$}

The $\mathrm{Sm}^{3+}$-derivative exhibits luminescence in the visible but also in the infra-red domain. Accordingly, room-temperature solid-state excitation spectrum $\left(\lambda_{\mathrm{em}}=642 \mathrm{~nm}\right)$ and emission spectra in both the visible and the IR domains $\left(\lambda_{\text {exc }}=303 \mathrm{~nm}\right)$ have been recorded and are reported in Figure 5. Excitation spectrum shows a broad band centered at $303 \mathrm{~nm}$ similar to the one observed for $\left[\mathrm{Eu}_{2}(\mathrm{dcpa})_{3}\left(\mathrm{H}_{2} \mathrm{O}\right)\right]_{\infty}$ that evidences that the ligand act as an efficient antenna for $\left[\mathrm{Sm}_{2}(\mathrm{dcpa})_{3}\left(\mathrm{H}_{2} \mathrm{O}\right)\right]_{\infty}$ as well. Emission spectrum recorded in the visible domain shows the characteristic emission peaks of $\mathrm{Sm}^{3+}$ that correspond to ${ }^{4} \mathrm{G}_{5 / 2} \rightarrow{ }^{6} \mathrm{H}_{5 / 2-13 / 2}$ transitions $\left(\tau_{\mathrm{obs}}=0.6(1) \mu \mathrm{s}\right){ }^{65}$ It is noteworthy that emission intensity is so weak that no quantum yield measurement has been possible with our setup. Emission spectrum in the IR 
domain also shows the characteristic emission peaks of $\mathrm{Sm}^{3+}$ that correspond to ${ }^{4} \mathrm{G}_{5 / 2} \rightarrow{ }^{6} \mathrm{H}_{15 / 2}$ and ${ }^{4} \mathrm{G}_{5 / 2} \rightarrow{ }^{6} \mathrm{~F}_{1 / 2-11 / 2}$ transitions.
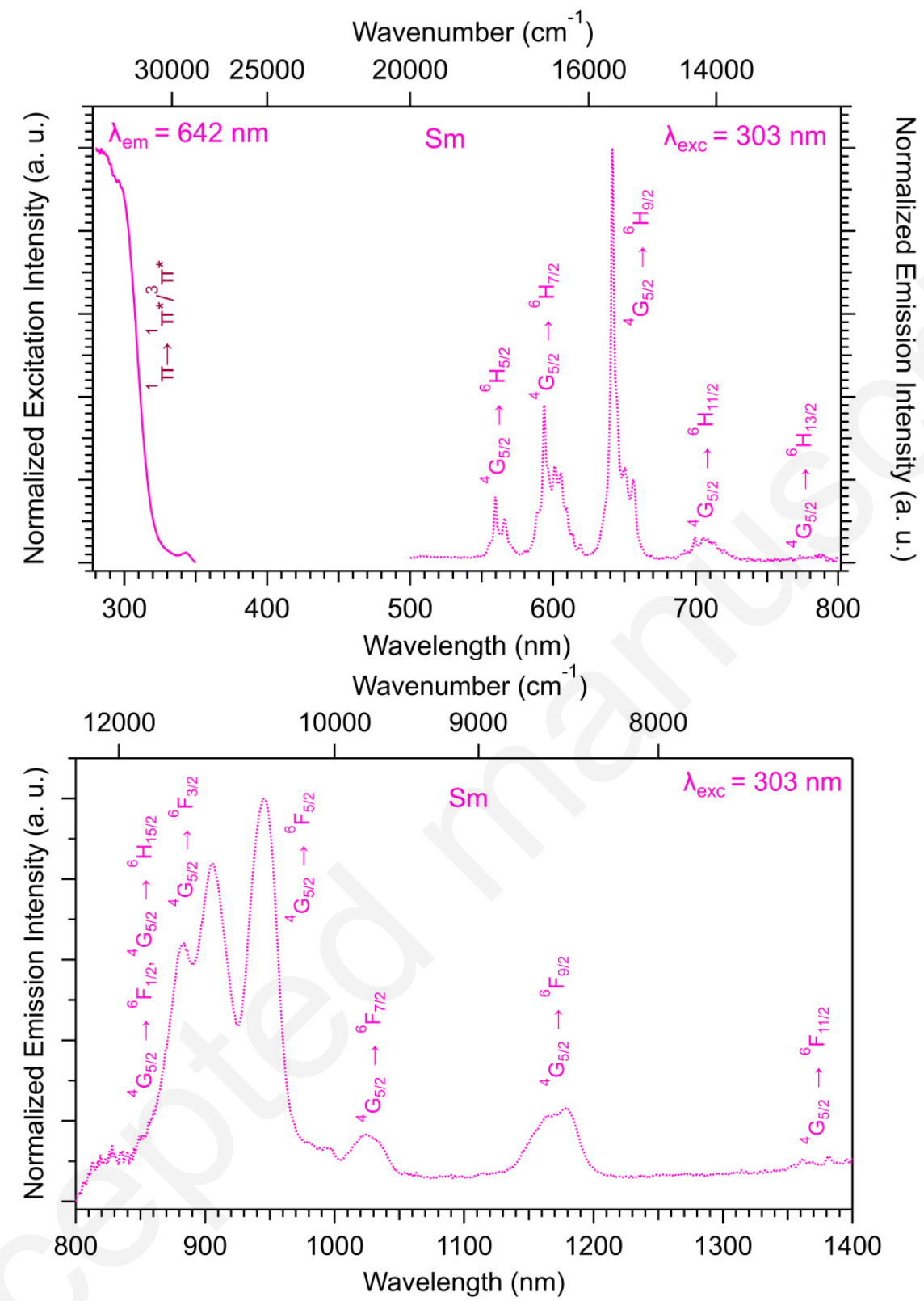

Figure 5. Room-temperature solid-state excitation $\left(\lambda_{\mathrm{em}}=642 \mathrm{~nm}\right)$ and emission $\left(\lambda_{\text {exc }}=303 \mathrm{~nm}\right)$ spectra in the visible domain of $\left[\mathrm{Sm}_{2}(\mathrm{dcpa})_{3}\left(\mathrm{H}_{2} \mathrm{O}\right)\right]_{\infty}$ (top). Room-temperature solid-state emission $\left(\lambda_{\text {exc }}=303 \mathrm{~nm}\right)$ spectrum in the IR domain of $\left[\mathrm{Sm}_{2}(\mathrm{dcpa})_{3}\left(\mathrm{H}_{2} \mathrm{O}\right)\right]_{\infty}$ (bottom).

Room-temperature solid-state excitation and emission spectra of both the Pr- and the Nd-derivatives have also been recorded (Figure 6). Excitation spectra indicate that again the antenna effect is efficient for both compounds. 
Emission spectrum of $\left[\operatorname{Pr}_{2}(\mathrm{dcpa})_{3}\left(\mathrm{H}_{2} \mathrm{O}\right)\right]_{\infty}$ shows the characteristic peaks of the $\operatorname{Pr}^{3+}$ ion that correspond to ${ }^{3} \mathrm{P}_{1-0} \rightarrow{ }^{3} \mathrm{H}_{6-4}$ and ${ }^{3} \mathrm{P}_{1-0} \rightarrow{ }^{3} \mathrm{~F}_{4-2}$ transitions. ${ }^{66}$ It is noticeable that these emission peaks in the visible domain are rarely observed and Pr-based coordination polymers that exhibit such a well-defined emission spectrum are rare. ${ }^{38,}$ 64, 67-68 Emission spectrum, in the IR domain, of $\left[\mathrm{Nd}_{2}(\mathrm{dcpa})_{3}\left(\mathrm{H}_{2} \mathrm{O}\right)\right]_{\infty}$ shows the characteristic peaks of $\mathrm{Nd}^{3+}$ that correspond to ${ }^{4} \mathrm{~F}_{3 / 2} \rightarrow{ }^{4} \mathrm{I}_{9 / 2-13 / 2}$ transitions. ${ }^{66}$
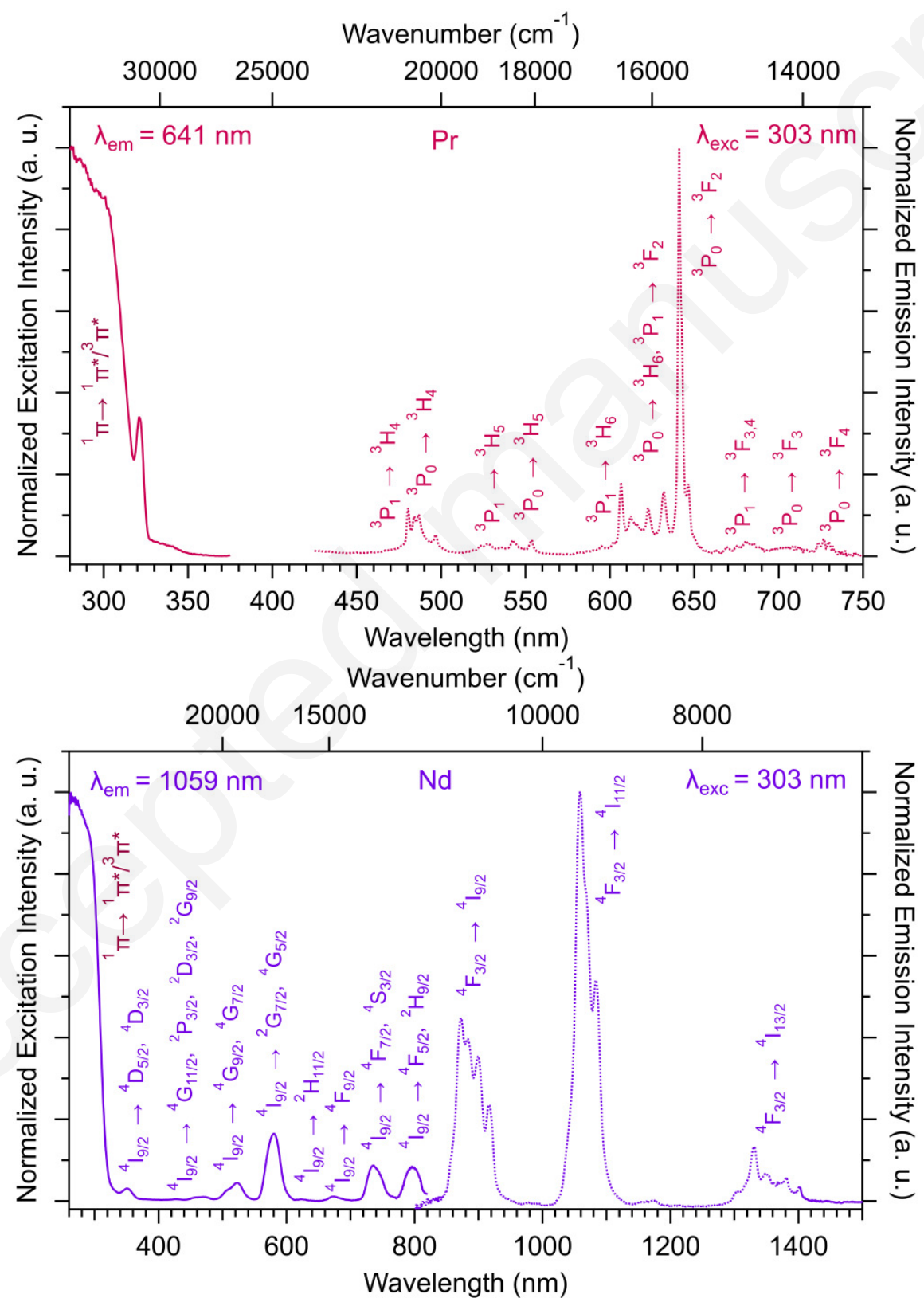

Figure 6. Room-temperature solid-state excitation $\left(\lambda_{\mathrm{em}}=641 \mathrm{~nm}\right.$ and $1059 \mathrm{~nm}$ for the red and purple solid curves, respectively) and emission $\left(\lambda_{\text {exc }}=303 \mathrm{~nm}\right)$ spectra of $\left[\operatorname{Pr}_{2}(\mathrm{dcpa})_{3}\left(\mathrm{H}_{2} \mathrm{O}\right)\right]_{\infty}$ in the visible domain (top) and of $\left[\mathrm{Nd}_{2}(\mathrm{dcpa})_{3}\left(\mathrm{H}_{2} \mathrm{O}\right)\right]_{\infty}$ in the IR domain (bottom). 
Brightness enhancement: $\left[\operatorname{Ln}_{2-2 x} \operatorname{La} a_{2 x}(d c p a)_{3}\left(H_{2} O\right)\right]_{\infty}$ with $\mathbf{L n}=\operatorname{Pr}-E u($ except Pm) and $\mathbf{0} \leq \boldsymbol{x} \leq 1$

It is commonly admitted that inter-metallic energy transfers are less efficient when lanthanide ions are more than $10 \AA$ far from each other. ${ }^{22}$ As underlined in the structural part, in this family of compounds, there are 13 lanthanide ions closer than $10 \AA$ from a given lanthanide ion and all of them belong to the same molecular layer. Therefore, it is, theoretically, possible to enhance the luminescence intensity by diluting optically-active lanthanide ions by optically inactive ones. In our case we have used $\mathrm{La}^{\mathrm{III}}$ as optically inactive ion and we have prepared four series of hetero-di-lanthanide coordination polymers with respective general chemical formulas $\left[\operatorname{Pr}_{2-2 x} \operatorname{La}_{2 x}(\mathrm{dcpa})_{3}\left(\mathrm{H}_{2} \mathrm{O}\right)\right]_{\infty}, \quad\left[\mathrm{Nd}_{2-2 x} \mathrm{La}_{2 x}(\mathrm{dcpa})_{3}\left(\mathrm{H}_{2} \mathrm{O}\right)\right]_{\infty}$, $\left[\mathrm{Sm}_{2}-2 x \mathrm{La}_{2 x}(\mathrm{dcpa})_{3}\left(\mathrm{H}_{2} \mathrm{O}\right)\right]_{\infty}$ and $\left[\mathrm{Eu}_{2}-2 x \mathrm{La}_{2 x}(\mathrm{dcpa})_{3}\left(\mathrm{H}_{2} \mathrm{O}\right)\right]_{\infty}$ with $0 \leq x \leq 1$. Iso-structurality of these compounds with $\left[\mathrm{Eu}_{2}(\mathrm{dcpa})_{3}\left(\mathrm{H}_{2} \mathrm{O}\right)\right]_{\infty}$ has been assumed on the basis of their powder X-ray diffraction diagrams (Figures S3 to S6) and the relative contents of the two lanthanide ions have been estimated on the basis of EDS measurements (Tables S1 to S4).

Emission spectra of the compounds with general chemical formula $\left[\mathrm{Eu}_{2-2 x} \operatorname{La}_{2 x}(\mathrm{dcpa})_{3}\left(\mathrm{H}_{2} \mathrm{O}\right)\right]_{\infty}$ with $0 \leq x \leq 1$ have been recorded $\left(\lambda_{\text {exc }}=303 \mathrm{~nm}\right)($ Figure 7$)$. Their luminance $\left(\lambda_{\mathrm{exc}}=312 \mathrm{~nm}\right)$ has been measured as well (Figure S19). Figure 7 shows that luminescence intensity is almost constant whatever $x$ is. This is in agreement with the crystal structure. Indeed, for a given $\mathrm{Eu}^{3+}$ ion, if one wants to substitute the 13 nearest neighbors by $\mathrm{La}^{3+}$ ions, the $x$ value should be at least 0.93 . This is actually what is observed and the luminescence intensity is roughly identical between $x=0$ and $x=0.9$. This is interesting as far as potential industrial applications are targeted because lanthanum is much cheaper than europium. This behavior is quite unusual and generally, for $\mathrm{La} / \mathrm{Eu}$-based hetero-lanthanide coordination polymers, the decreasing of the number of luminescent centers is not fully 
compensated by the decreasing of inter-metallic energy transfers. ${ }^{30,} 39-40$ This suggests that inter-metallic energy transfers are very strong and that particularly high $\mathrm{La}^{\mathrm{III}}$ content is required to suppress them in this system. Consequently, the dilution of optically active lanthanide ions by optically inactive ones constitutes a very efficient strategy.

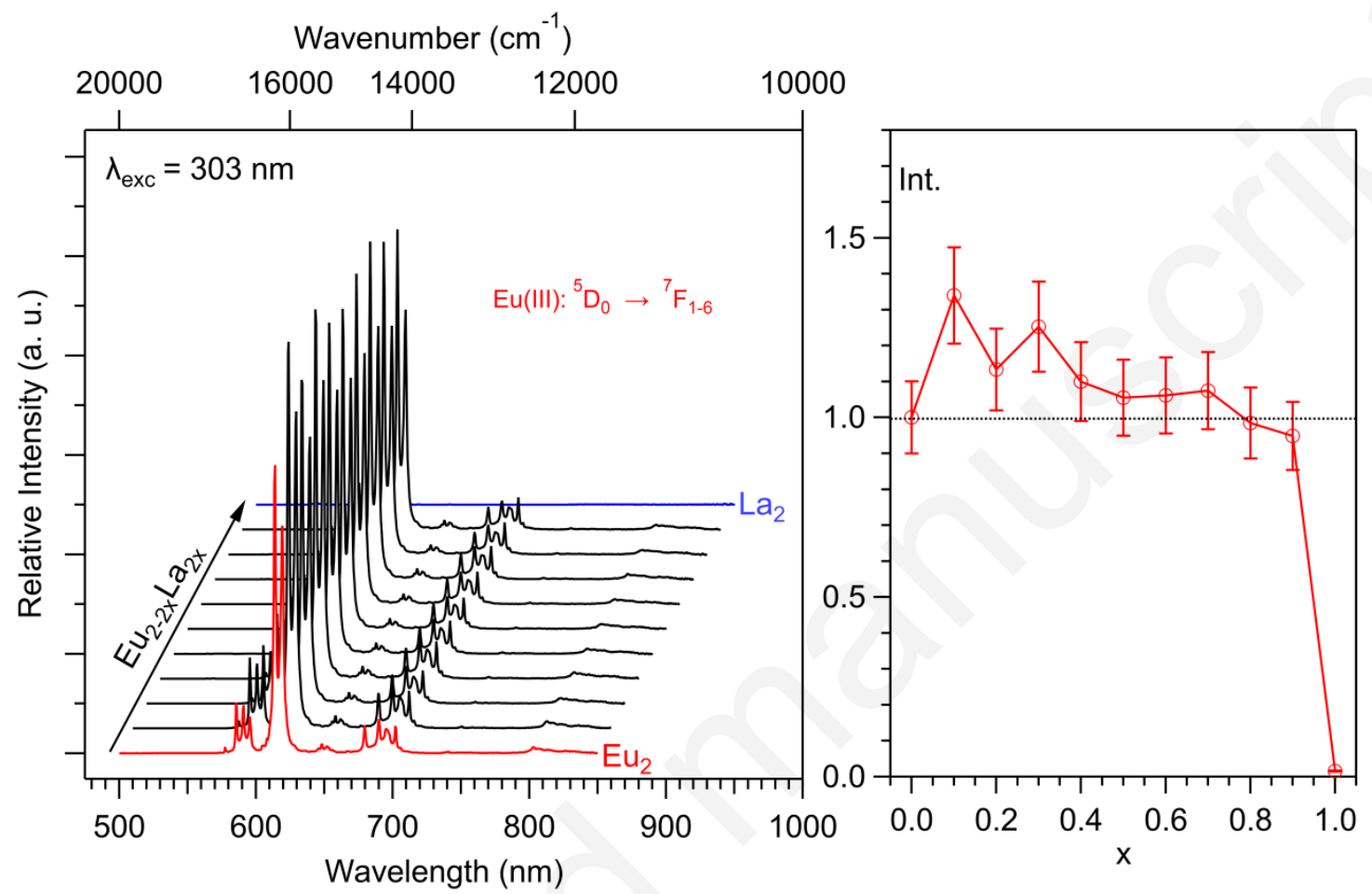

Figure 7. Left: room-temperature solid-state emission spectra of $\left[\mathrm{Eu}_{2-2 \mathrm{x}} \mathrm{La}_{2 \mathrm{x}}(\mathrm{dcpa})_{3}\left(\mathrm{H}_{2} \mathrm{O}\right)\right]_{\infty}$ with $0 \leq x \leq 1 \quad\left(\lambda_{\text {exc }}=303 \mathrm{~nm}\right)$. Right: integrated intensity of all the observed $\mathrm{Eu}^{3+}$ transitions versus $x$ (step is 0.1 ). Integrated intensity of $\left[\mathrm{Eu}_{2}(\mathrm{dcpa})_{3}\left(\mathrm{H}_{2} \mathrm{O}\right)\right]_{\infty}$ is set to 1 .

In order to verify this assumption, emission spectra of $\mathrm{La} / \mathrm{Pr}-, \mathrm{La} / \mathrm{Nd}-$ and $\mathrm{La} / \mathrm{Sm}$-derivatives have been recorded (Figures 8 and 9). 

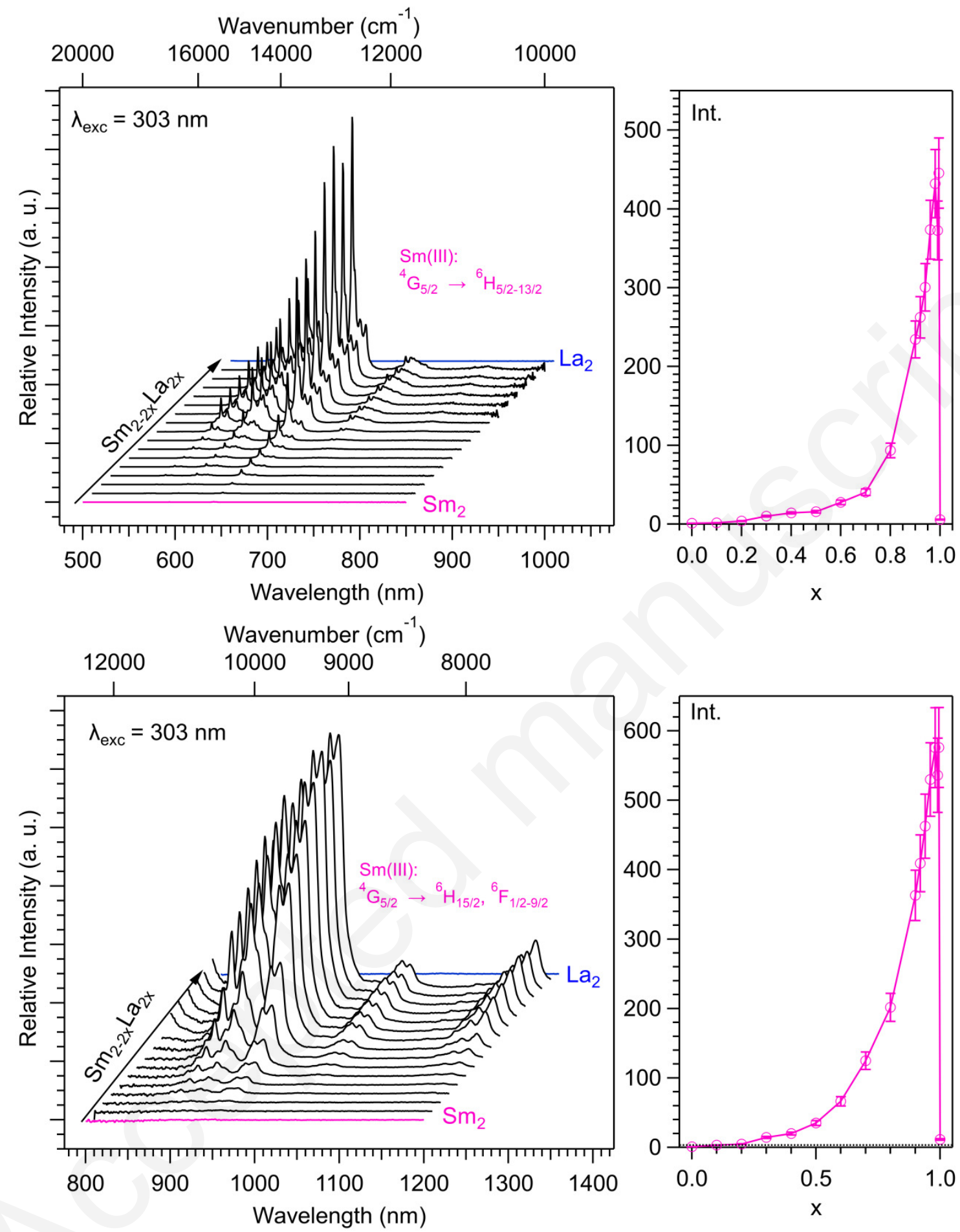

Figure 8. Left: Room-temperature solid-state emission spectra of $\left[\mathrm{Sm}_{2-2 x} \mathrm{La}_{2 x}(\mathrm{dcpa})_{3}\left(\mathrm{H}_{2} \mathrm{O}\right)\right]_{\infty}$ with $0 \leq x \leq 1 \quad\left(\lambda_{\mathrm{exc}}=303 \mathrm{~nm}\right)$ in the visible (top) and IR (bottom) domains. Right: integrated intensities of all the observed transitions of $\mathrm{Sm}^{3+}$ in the visible and in the IR, respectively, versus $x$ (step $=0.1$ between $x=0$ and 0.9 , and step $=0.02$ between $x=0.9$ and 1). Integrated intens ity of $\left[\mathrm{Sm}_{2}(\mathrm{dcpa})_{3}\left(\mathrm{H}_{2} \mathrm{O}\right)\right]_{\infty}$ is set to 1 . 
Figure 8 evidences that the brightness enhancement by dilution is much more efficient for the $\mathrm{La} / \mathrm{Sm}$-series than for the $\mathrm{La} / \mathrm{Eu}$-series. Indeed the intensity of the luminescence of $\left[\mathrm{Sm}_{0.04} \mathrm{La}_{1.96}(\mathrm{dcpa})_{3}\left(\mathrm{H}_{2} \mathrm{O}\right)\right]_{\infty}$ is 432 times and 576 times greater than that of $\left[\mathrm{Sm}_{2}(\mathrm{dcpa})_{3}\left(\mathrm{H}_{2} \mathrm{O}\right)\right]_{\infty}$ in the visible and in the IR domains, respectively. Enhancement by dilution effect of the $\mathrm{Sm}^{3+}$ luminescence has already been reported but with a much lower extend. ${ }^{69}$ This very strong enhancement of the luminescence intensity by dilution effect was unexpected and is, to the best of our knowledge, unprecedented. Overall quantum yield of $\left[\mathrm{Sm}_{0.04} \mathrm{La}_{1.96}(\mathrm{dcpa})_{3}\left(\mathrm{H}_{2} \mathrm{O}\right)\right]_{\infty}$ in the visible domain has been measured. It reaches $9.2(2) \%$ which is, for a $\mathrm{Sm}^{3+}$ coordination compound, a remarkable value when compared with the literature (Table 1). The luminescence lifetime also increases a lot with a measured value of $0.38(1) \mathrm{ms}$ for $\left[\mathrm{Sm}_{0.2} \mathrm{La}_{1.8}(\mathrm{dcpa})_{3}\left(\mathrm{H}_{2} \mathrm{O}\right)\right]_{\infty}$ compared to $0.6(1) \mu \mathrm{s}$ for $\left[\mathrm{Sm}_{2}(\mathrm{dcpa})_{3}\left(\mathrm{H}_{2} \mathrm{O}\right)\right]_{\infty}$. Luminance under irradiation of this series of compounds has also been measured (Figure S20). These measurements shows a very abrupt increase of the luminance with $x$ and luminance for $\left[\mathrm{Sm}_{0.04} \mathrm{La}_{1.96}(\mathrm{dcpa})_{3}\left(\mathrm{H}_{2} \mathrm{O}\right)\right]_{\infty}$ is greater than $15 \mathrm{Cd} \cdot \mathrm{m}^{-2}$.

\begin{tabular}{|c|c|c|c|}
\hline Chemical formula & $Q_{\text {Sm }}^{\text {Ligand }}(\%)$ & $\lambda_{\text {exc }}(\mathrm{nm})$ & Reference \\
\hline$\left[\mathrm{Sm}_{2}(\mathrm{cam})_{2}(\mathrm{bdc}) \cdot\left(\mathrm{H}_{2} \mathrm{O}\right)_{2} \cdot \mathrm{dmf}\right]_{\infty}$ & 5.2 & 280 & 70 \\
\hline$\left[\mathrm{Sm}(\mathrm{bcpba})\left(\mathrm{H}_{2} \mathrm{O}\right)\right]_{\infty}$ & 17 & 259 & 71 \\
\hline$\left[\mathrm{Sm}(\mathrm{tfbdc})_{1.5}\left(\mathrm{H}_{2} \mathrm{O}\right)_{2} \cdot \mathrm{H}_{2} \mathrm{O}\right]_{\infty}$ & 0.73 & 364 & 72 \\
\hline$\left[\mathrm{Sm}(\text { tpia })\left(\mathrm{H}_{2} \mathrm{O}\right)_{3} \cdot 5.5 \mathrm{H}_{2} \mathrm{O}\right]_{\infty}$ & 1.8 & 358 & 73 \\
\hline$\left[\mathrm{Sm}(\mathrm{dpdc})_{1.5}(\mathrm{ip})\left(\mathrm{H}_{2} \mathrm{O}\right)\right]_{\infty}$ & 1.76 & 330 & 74 \\
\hline$\left.\left[\mathrm{Sm}_{2} \text { (mip) }\right)_{3}\left(\mathrm{H}_{2} \mathrm{O}\right)_{8} \cdot 4 \mathrm{H}_{2} \mathrm{O}\right]_{\infty}$ & 0.18 & 325 & 38 \\
\hline$\left[\mathrm{Sm}_{2}(\mathrm{Hshi})_{2}(\mathrm{dbm})_{4} \cdot 2 \mathrm{dmf}\right]$ & 0.8 & 355 & 69 \\
\hline$\left[\mathrm{Sm}_{0.1} \mathrm{Gd}_{1.9}(\mathrm{Hshi})_{2}(\mathrm{dbm})_{4} \cdot 2 \mathrm{dmf}\right]$ & 2.4 & 355 & 69 \\
\hline$\left[\mathrm{Sm}_{2}(\mathrm{dcpa})_{3}\left(\mathrm{H}_{2} \mathrm{O}\right)\right]_{\infty}$ & $<0.1$ & 303 & This work \\
\hline$\left[\mathrm{Sm}_{0.04} \mathrm{La}_{1.96}(\mathrm{dcpa})_{3}\left(\mathrm{H}_{2} \mathrm{O}\right)\right]_{\infty}$ & 9.2 & 303 & This work \\
\hline \multicolumn{4}{|c|}{$\begin{array}{l}\text { bdc = benzenedicarboxylate; cam = camphorate; } \\
\text { bcpba =3,5-bi(4-carboxy-phenoxy)-benzoate; thdc =2,3,5,6-tetrafluoroterephthalate; } \\
\text { tpia = 5-(4-(tetrazol-5-yl)phenoxy)isophthalate; dpdc }=2,2 \text { 'diphenyldicarboxylate; } \\
\text { ip = 1H-imidazo[4,5][1,10]-phenantroline; shi = salicylhydroxamate; } \\
\text { dbm = dibenzoylmethanide; mip = methoxyisophthalate }\end{array}$} \\
\hline
\end{tabular}


Dilution effect for the compounds that constitute the $\mathrm{La} / \mathrm{Pr}$ and $\mathrm{La} / \mathrm{Nd}$ series is intermediate between the behavior of the $\mathrm{La} / \mathrm{Eu}$-based compounds and that of the La/Sm-based ones (Figure 9). In both cases, maximum intensity is reached for $\mathrm{x} \approx 0.9$ but maximum enhancement factor is about 4.9 in the visible domain and about 234 in the IR domain for $\mathrm{La} / \mathrm{Pr}$ series and is only about 2.3 for $\mathrm{La} / \mathrm{Nd}$ series.
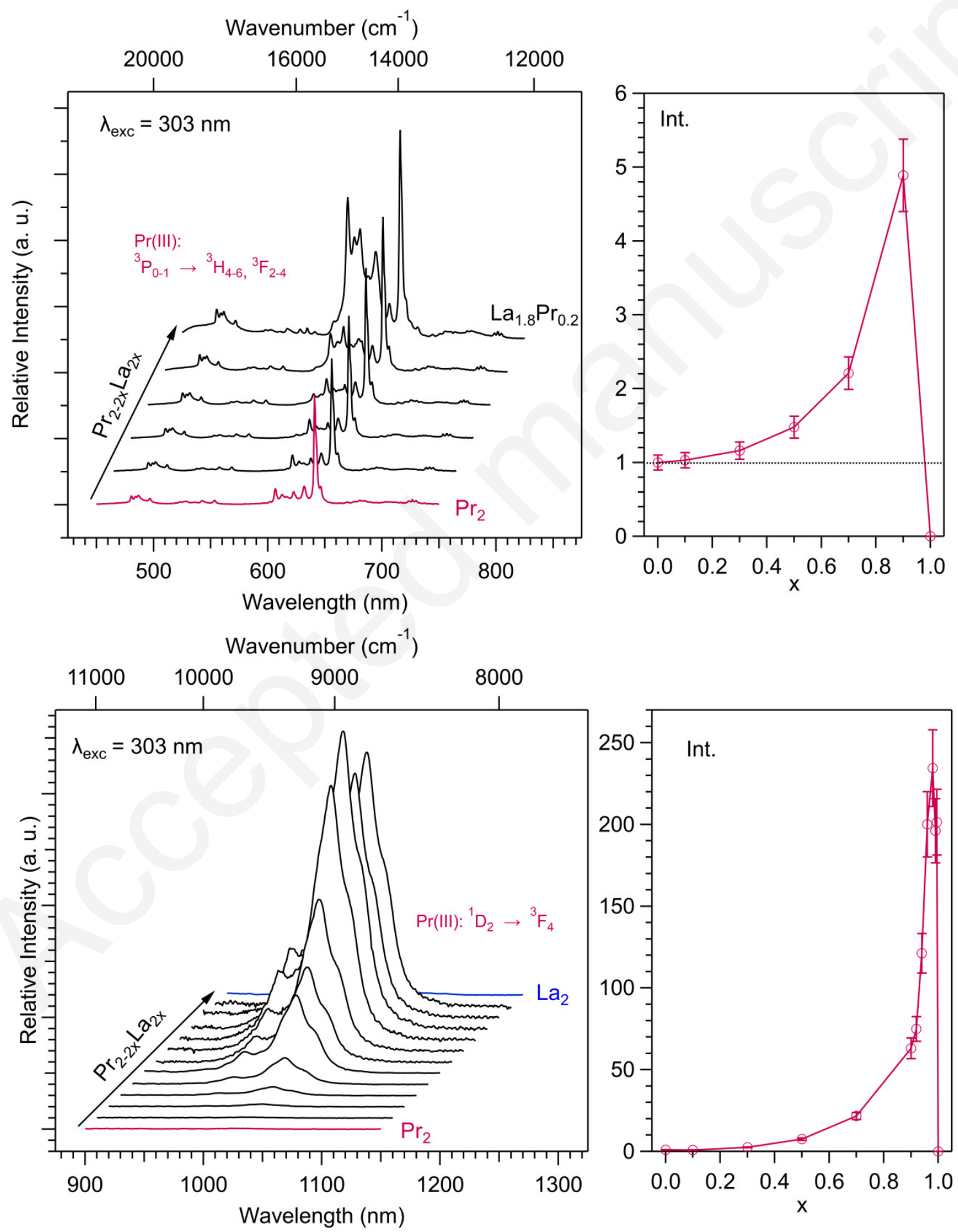

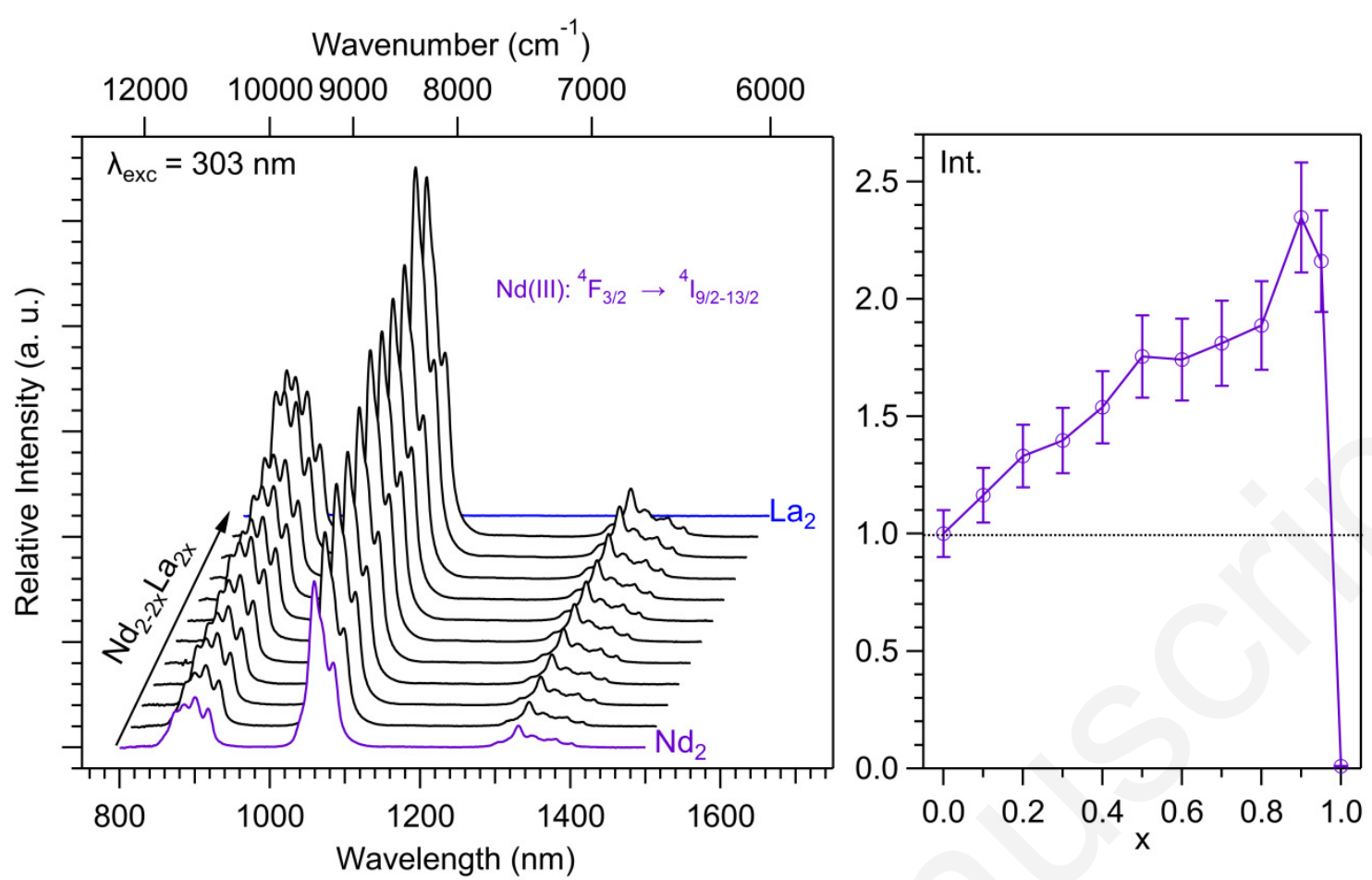

Figure 9. Room-temperature solid-state emission spectra of $\left[\operatorname{Pr}_{2-2 x} L_{2 x}(d c p a)_{3}\left(H_{2} \mathrm{O}\right)\right]_{\infty}$ (top and middle for visible and IR, respectively) and $\left[\mathrm{Nd}_{2-2 x} \mathrm{La}_{2 x}(\mathrm{dcpa})_{3}\left(\mathrm{H}_{2} \mathrm{O}\right)\right]_{\infty}$ (bottom) with $0 \leq x \leq 1 \quad\left(\lambda_{\text {exc }}=303 \mathrm{~nm}\right)$. Integrated intensities of all the observed transitions for $\operatorname{Pr}^{3+}$ in the visible and in the IR, respectively (top and middle right), and for $\mathrm{Nd}^{3+}$ in the IR (bottom right) versus $x$. Integrated intensities of $\left[\operatorname{Pr}_{2}(\mathrm{dcpa})_{3}\left(\mathrm{H}_{2} \mathrm{O}\right)\right]_{\infty}$ and $\left[\mathrm{Nd}_{2}(\mathrm{dcpa})_{3}\left(\mathrm{H}_{2} \mathrm{O}\right)\right]_{\infty}$ are set to 1 .

As far as dilution effect is concerned, these four series of iso-structural hetero-lanthanide coordination polymers exhibit drastically different behaviors (Tables 2 and S13).

Table 2. Maximum integrated area of the emission peaks of $\left[\operatorname{Pr}_{0.04} \mathrm{La}_{1.96}(\mathrm{dcpa})_{3}\left(\mathrm{H}_{2} \mathrm{O}\right)\right]_{\infty}$, $\left[\mathrm{Nd}_{0.2} \mathrm{La}_{1.8}(\mathrm{dcpa})_{3}\left(\mathrm{H}_{2} \mathrm{O}\right)\right]_{\infty},\left[\mathrm{Sm}_{0.04} \mathrm{La}_{1.96}(\mathrm{dcpa})_{3}\left(\mathrm{H}_{2} \mathrm{O}\right)\right]_{\infty}$ and $\left[\mathrm{Eu}_{1.8} \mathrm{La}_{0.2}(\mathrm{dcpa})_{3}\left(\mathrm{H}_{2} \mathrm{O}\right)\right]_{\infty}$ with $0 \leq x \leq 1$ series.

\begin{tabular}{lcc}
\hline \multicolumn{1}{c}{ Compound } & $\begin{array}{c}\text { Visible } \\
\text { integrated area* }\end{array}$ & $\begin{array}{c}\text { Infra-red } \\
\text { integrated area* }\end{array}$ \\
\hline$\left[\mathrm{Pr}_{0.04} \mathrm{La}_{1.96}(\mathrm{dcpa})_{3}\left(\mathrm{H}_{2} \mathrm{O}\right)\right]_{\infty}$ & 4.9 & 234 \\
{$\left[\mathrm{Nd}_{0.2} \mathrm{La}_{1.8}(\mathrm{dcpa})_{3}\left(\mathrm{H}_{2} \mathrm{O}\right)\right]_{\infty}$} & - & 2.3 \\
{$\left[\mathrm{Sm}_{0.04} \mathrm{La}_{1.96}(\mathrm{dcpa})_{3}\left(\mathrm{H}_{2} \mathrm{O}\right)\right]_{\infty}$} & 432 & 576 \\
{$\left[\mathrm{Eu}_{1.8} \mathrm{La} 0.2(\mathrm{dcpa})_{3}\left(\mathrm{H}_{2} \mathrm{O}\right)\right]_{\infty}$} & 1.3 & - \\
\hline$*$ Integrated area of the & corresponding & transitions \\
compounds are set to 1. & & measured for the homo-lanthanide \\
\hline
\end{tabular}

Because all the compounds are iso-structural, these results suggest that de-excitation pathways are strongly dependent of the relative energies of the different states of the lanthanide ions (Scheme 4). 

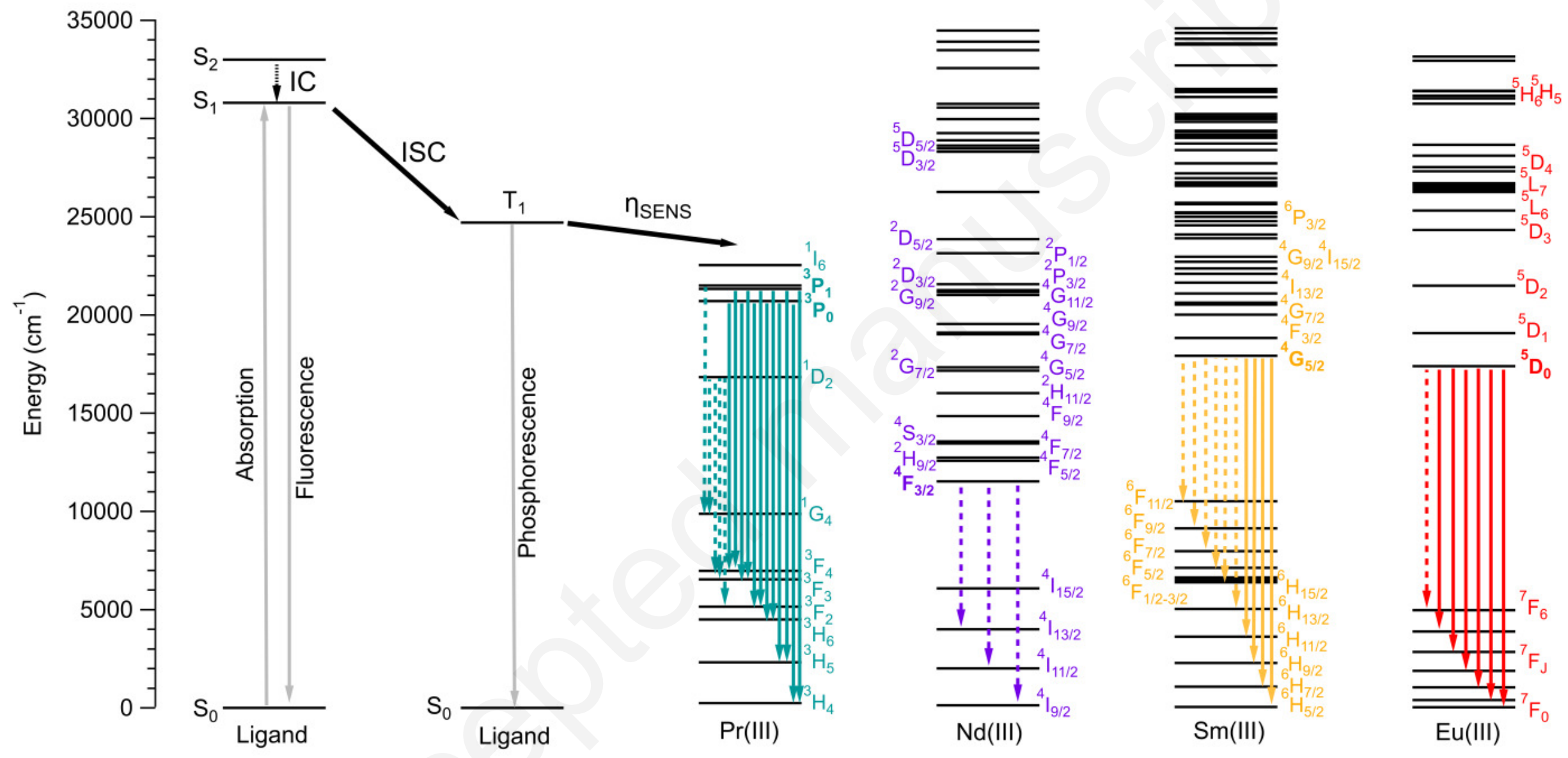

Scheme 4. Schematic representation of the energy levels of the dcpa ${ }^{2-}$ ligand and of $\mathrm{Pr}^{3+}, \mathrm{Nd}^{3+}, \mathrm{Sm}^{3+}$ and $\mathrm{Eu}^{3+}$ ions. Broken arrows symbolize

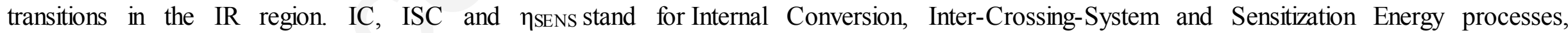
respectively. S and T stand for Singlet and Triplet states, respectively. 
Differences in enhancement factor were expected because non-radiative deactivation process is most often dominated by vibrational deactivation. Indeed the energy gap between emissive and receiving $\mathrm{Ln}^{3+}$ states can be bridged by high energy vibrators $(\mathrm{O}-\mathrm{H}, \mathrm{C}-\mathrm{H}, \mathrm{C}=\mathrm{O}$, $\mathrm{C}-\mathrm{O}, \mathrm{C}=\mathrm{C} \ldots$ or their overtones $)^{23}$ that are necessary present in coordination compounds. On the other hand, extent of these differences was unexpected. It suggests that relative influence of vibrational deactivation process toward inter-metallic quenching vary in a large extent from a lanthanide ion to another. Because both mechanisms are thermo-dependent emission spectra of $\left[\mathrm{Ln}_{2}(\mathrm{dcpa})_{3}\left(\mathrm{H}_{2} \mathrm{O}\right)\right]_{\infty}$ and $\left[\mathrm{Ln}_{0.2} \mathrm{La}_{1.8}(\mathrm{dcpa})_{3}\left(\mathrm{H}_{2} \mathrm{O}\right)\right]_{\infty}$ with $\mathrm{Ln}=\mathrm{Pr}, \mathrm{Nd}, \mathrm{Sm}$ or Eu have been recorded versus temperature between $77 \mathrm{~K}$ and $300 \mathrm{~K}$ (Figures S21-S24). These measurements evidences that both inter-metallic energy transfers and vibrational de-activation strongly depend on the considered lanthanide ion. However, these results indicate that the influence of the temperature on the emission spectra of the La-doped compounds is unexpectedly weak (fluctuations are only about 10\% - Figure S25) when compared with similar coordination polymers. ${ }^{49}$ This could be related to the rigid molecular framework that limits vibrations, and possibly non-radiative de-excitation in this family of compounds.

\section{Investigation of the energy transfers in hetero-lanthanide-based coordination polymers.}

Because of this unexpectedly strong dilution effect, a study of the inter-metallic energy transfers that take place in hetero-lanthanide based coordination polymers that involve two optically active lanthanide ions have been undertaken. In order to evaluate the relevance of a "cascade effect" strategy, ${ }^{75}$ Eu-containing series have been studied because $\left[\mathrm{Eu}_{2}(\mathrm{dcpa})_{3}\left(\mathrm{H}_{2} \mathrm{O}\right)\right]_{\infty}$ exhibits the most important overall quantum yield of the homo-lanthanide coordination polymers that belong to this series of compounds. Therefore, $\left[\operatorname{Pr}_{2-2 x} \mathrm{Eu}_{2 x}(\mathrm{dcpa})_{3}\left(\mathrm{H}_{2} \mathrm{O}\right)\right]_{\infty}, \quad\left[\mathrm{Nd}_{2-2 x} \mathrm{Eu}_{2 \mathrm{x}}(\mathrm{dcpa})_{3}\left(\mathrm{H}_{2} \mathrm{O}\right)\right]_{\infty}$ and $\left[\mathrm{Sm}_{2-2 \mathrm{x}} \mathrm{Eu}_{2 \mathrm{x}}(\mathrm{dcpa})_{3}\left(\mathrm{H}_{2} \mathrm{O}\right)\right]_{\infty}$ with 
$x=0.25,0.5$ and 0.75 have been prepared. Their metallic compositions were determined by EDS measurements (Tables S5 to S7). Their iso-structurality with $\left[\mathrm{Eu}_{2}(\mathrm{dcpa})_{3}\left(\mathrm{H}_{2} \mathrm{O}\right)\right]_{\infty}$ was assumed on the basis of their powder X-ray diffraction diagrams (Figures S7 to S9). Their emission spectra have been recorded in both the visible and the IR domains (Figures S26, S27 and $\mathrm{S} 28$ for $\left[\mathrm{Nd}_{2-2 x} \mathrm{Eu}_{2 x}(\mathrm{dcpa})_{3}\left(\mathrm{H}_{2} \mathrm{O}\right)\right]_{\infty},\left[\operatorname{Pr}_{2-2 x} \mathrm{Eu}_{2 x}(\mathrm{dcpa})_{3}\left(\mathrm{H}_{2} \mathrm{O}\right)\right]_{\infty},\left[\mathrm{Sm}_{2}-2 x \mathrm{Eu}_{2 x}(\mathrm{dcpa})_{3}\left(\mathrm{H}_{2} \mathrm{O}\right)\right]_{\infty}$ series, respectively). They show similar behaviors and therefore only that of $\left[\mathrm{Nd}_{2-2 \mathrm{x}} \mathrm{Eu}_{2 \mathrm{x}}(\mathrm{dcpa})_{3}\left(\mathrm{H}_{2} \mathrm{O}\right)\right]_{\infty}$ with $x=0.25,0.5$ and 0.75 is described below.

Emission spectra of the compounds that belong to the $\mathrm{Nd} / \mathrm{Eu}$-based hetero lanthanide series shows a drastic decreasing of the intensity of the $\mathrm{Eu}^{3+}$ emission in both domains when the $\mathrm{Nd}^{3+}$ content increases. This suggests strong inter-metallic energy transfers. Inter-metallic energy transfers efficiency ( $\eta_{\mathrm{ET}}$ ) has been estimated according to the following relationship:43

$\eta_{\mathrm{ET}}=1-\frac{\tau_{\mathrm{obs}}}{\tau_{0}}$

where $\tau_{\mathrm{obs}}$ and $\tau_{0}$ are the observed lifetimes of the donor luminescence in presence and in absence of an acceptor, respectively. Therefore $\mathrm{Eu}^{3+}$-luminescence lifetimes of $\left[\mathrm{Nd}_{2-2 \mathrm{x}} \mathrm{Eu}_{2 \mathrm{x}}(\mathrm{dcpa})_{3}\left(\mathrm{H}_{2} \mathrm{O}\right)\right]_{\infty}$ and $\left[\mathrm{La}_{2-2 \mathrm{x}} \mathrm{Eu}_{2 \mathrm{x}}(\mathrm{dcpa})_{3}\left(\mathrm{H}_{2} \mathrm{O}\right)\right]_{\infty}$ with $x=0.25,0.5$ and 0.75 have been measured and compared (Table 3).

Table 3. $\mathrm{Eu}^{3+}$-luminescence lifetimes of $\left[\mathrm{Nd}_{2-2 \mathrm{x}} \mathrm{Eu}_{2 \mathrm{x}}(\mathrm{dcpa})_{3}\left(\mathrm{H}_{2} \mathrm{O}\right)\right]_{\infty}\left(\tau_{\text {obs }}\right)$ with $x=0.25,0.5$, 0.75 and calculated inter-metallic energy transfers efficiency $\left(\eta_{\mathrm{ET}}\right)$.

\begin{tabular}{lccc}
\hline \multicolumn{1}{c}{ Compound } & $\tau_{\text {obs }}(\mathrm{ms})$ & $\tau_{0}{ }^{*}(\mathrm{~ms})$ & $\eta_{\mathrm{ET}}(\%)$ \\
\hline$\left[\mathrm{Nd}_{0.5} \mathrm{Eu}_{1.5}(\mathrm{dcpa})_{3}\left(\mathrm{H}_{2} \mathrm{O}\right)\right]_{\infty}$ & $0.12(3)$ & $1.42(1)$ & 92 \\
{$\left[\mathrm{Nd}_{1} \mathrm{Eu}_{1}(\mathrm{dcpa})_{3}\left(\mathrm{H}_{2} \mathrm{O}\right)\right]_{\infty}$} & $0.09(3)$ & $1.42(1)$ & 94 \\
{$\left[\mathrm{Nd}_{1.5} \mathrm{Eu}_{0.5}(\mathrm{dcpa})_{3}\left(\mathrm{H}_{2} \mathrm{O}\right)\right]_{\infty}$} & $0.06(3)$ & $1.42(1)$ & 96 \\
\hline${ }^{*} \tau_{0}$ corresponds to the luminescence lifetimes of $\left[\mathrm{La}_{2-2 \mathrm{E}} \mathrm{Eu}_{2 \mathrm{x}}(\mathrm{dcpa})_{3}\left(\mathrm{H}_{2} \mathrm{O}\right)\right]_{\infty}$ with $x=0.25,0.5$ \\
and 0.75
\end{tabular}

Table 3 shows that inter-metallic energy transfers efficiencies are very strong for all the compounds (Scheme 5). However, Figure S26 evidences that energy that is transferred from $\mathrm{Eu}^{3+}$ ions does not efficiently feed luminescent states of the $\mathrm{Nd}^{3+}$ ion. Indeed, $\left[\mathrm{Nd}_{2-2 x} \mathrm{Eu}_{2 \mathrm{x}}(\mathrm{dcpa})_{3}\left(\mathrm{H}_{2} \mathrm{O}\right)\right]_{\infty}$ exhibits almost no luminescence in the visible domain and a 
weaker luminescence, in the IR domain, than the pure $\mathrm{Nd}^{3+}$-derivative. Therefore there is no sizeable "cascade effect" and $\mathrm{Nd}^{3+}$ acts essentially as a quencher for $\mathrm{Eu}^{3+}$.

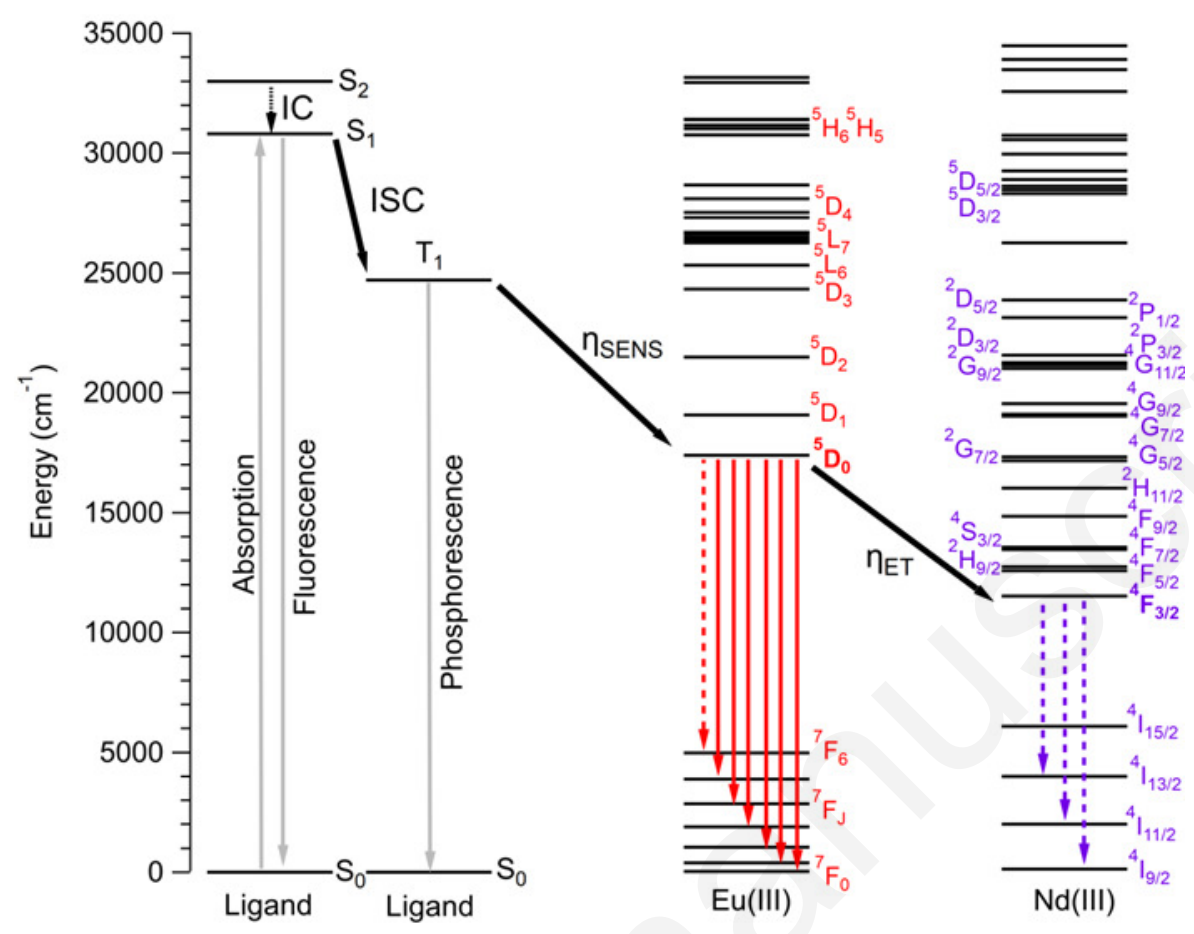

Scheme 5. Schematic representation of the energy transfer that occurs in $\left[\mathrm{Nd}_{2-2 x} \mathrm{Eu}_{2 x}(\mathrm{dcpa})_{3}\left(\mathrm{H}_{2} \mathrm{O}\right)\right]_{\infty}$ with $x=0.25,0.5$ and 0.75 . Broken arrows symbolize transitions in the IR region. IC, ISC and $\eta_{\text {SENS }}$ stand for Internal Conversion, Inter-Crossing-System and Sensitization Energy processes, respectively. $\mathrm{S}$ and $\mathrm{T}$ stand for Singlet and Triplet states, respectively.

Multi-emissive compounds: Hetero-lanthanide-based coordination polymers with a spacer $\left(\mathrm{La}^{3+}\right)$ and two optically active lanthanide ions $\left(\left[\operatorname{Ln}_{0.2-0.2 x} \mathrm{Eu}_{0.2 x}\right.\right.$ $\left.\operatorname{La}_{1.8}(\text { dcpa })_{3}\left(\mathrm{H}_{2} \mathrm{O}\right)\right]_{\infty}$ with $\mathrm{Ln}=\operatorname{Pr}-\mathrm{Sm}(\operatorname{except} \mathrm{Pm})$ and $0 \leq x \leq 1$.

On the basis of the results described above, we have prepared some hetero-tri-metallic molecular alloys with high lanthanum concentrations (90\%). Indeed, these high relative contents of an optically inactive lanthanide ion should allow the design of multi-emissive derivatives with sizeable brightness.

Therefore compounds with general chemical formula $\left[\operatorname{Ln}_{0.2-0.2 x} \operatorname{Eu}_{0.2 x} \operatorname{La}_{1.8}(\mathrm{dcpa})_{3}\left(\mathrm{H}_{2} \mathrm{O}\right)\right]_{\infty}$ with $0 \leq x \leq 1$ and $\mathrm{Ln}=\operatorname{Pr}-\mathrm{Sm}$ (except Pm) have been 
synthesized (Tables S8 to S10 and Figures S10 to S12). Their emission spectra have been recorded (Figures S29 to S31) and their luminance measured and compared with that of the hetero-di-lanthanide compounds that present identical $\mathrm{Eu} / \mathrm{Ln}$ ratios but no lanthanum (Figure 10). Their luminescence lifetimes have been measured as well and compared with those of the corresponding $\mathrm{Eu} / \mathrm{La}$-based compounds for which the Ln acceptor lanthanide ion has been substituted by lanthanum (Figure S13 and Table S11). Inter-metallic energy transfers efficiencies have been calculated according to relationship (3). Results are gathered in Table 4.
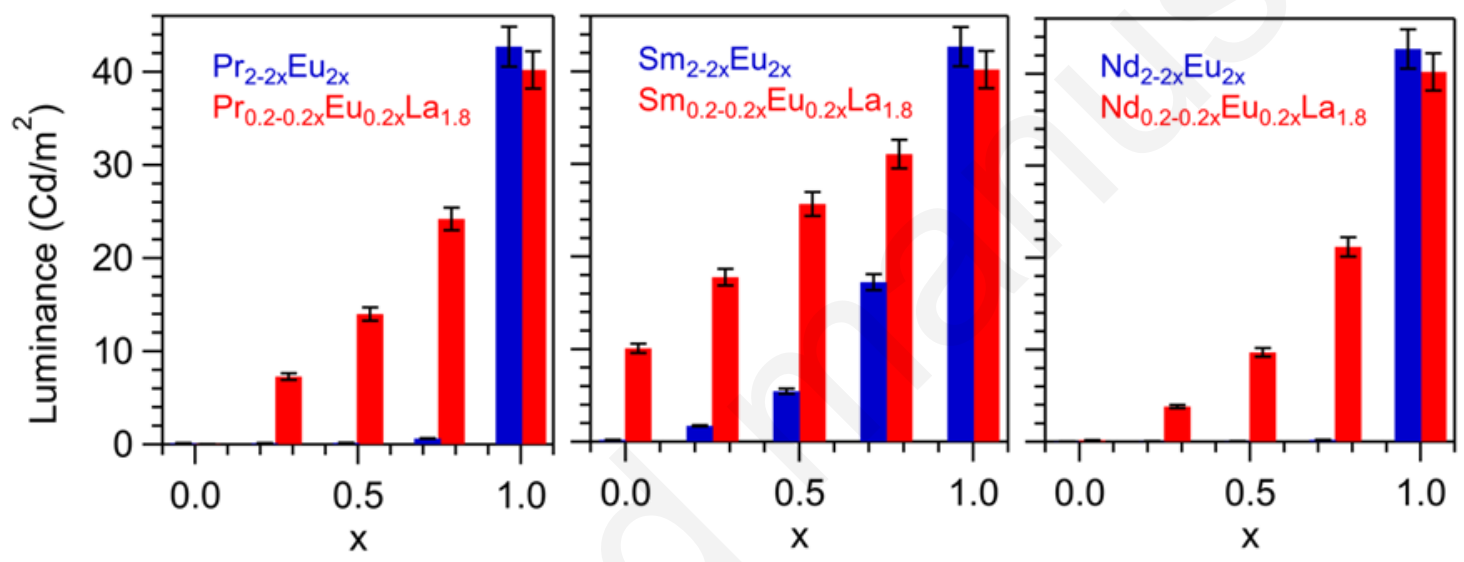

Figure 10. Luminance under UV irradiation $\left(\lambda_{\operatorname{exc}}=312 \mathrm{~nm}\right)$ of $\left[\operatorname{Ln}_{0.2-0.2 x} \mathrm{Eu}_{0.2 x} \mathrm{La}_{1.8}(\mathrm{dcpa})_{3}\left(\mathrm{H}_{2} \mathrm{O}\right)\right]_{\infty}$ and of $\left[\operatorname{Ln}_{2-2 x} \mathrm{Eu}_{2 x}(\mathrm{dcpa})_{3}\left(\mathrm{H}_{2} \mathrm{O}\right)\right]_{\infty}$ with $0 \leq x \leq 1$ and $\mathrm{Ln}=$ Pr-Sm except Pm vs $x$.

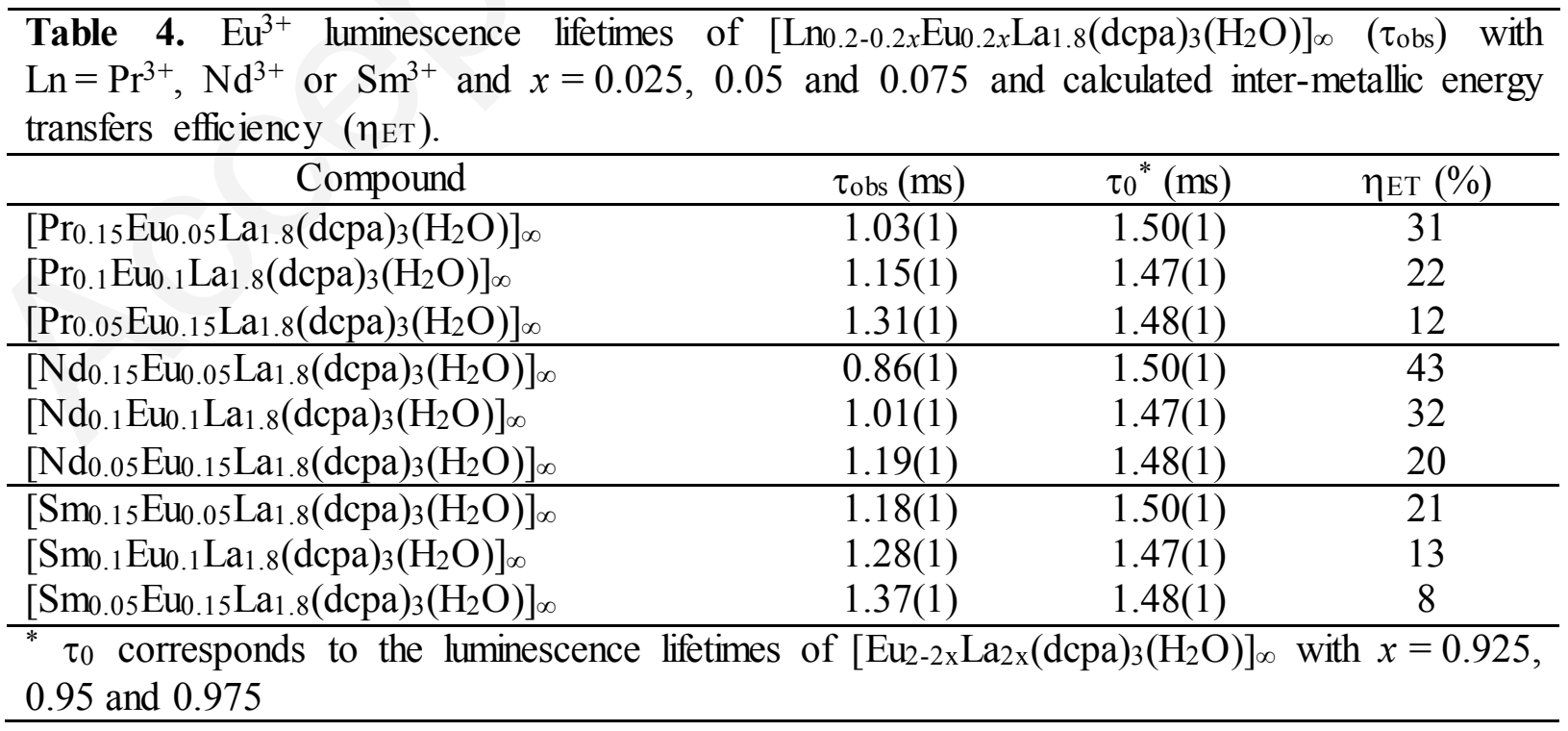


Figure 10 and Table 4 show that dilution by lanthanum provokes a drastic decrease of inter-metallic energy transfers and an important gain in luminance.

\section{Example of an optimized multi-emissive compound: Hetero-lanthanide-based} coordination polymer with a spacer $\left(\mathrm{La}^{3+}\right)$ and three optically active lanthanide ions: $\left[\mathrm{Nd}_{0.03} \mathrm{Sm}_{0.14} \mathrm{Eu}_{0.03} \mathrm{La}_{1.8}(\mathrm{dcpa})_{3}\left(\mathrm{H}_{2} \mathrm{O}\right)\right]_{\infty}$.

Behaviors of all the compounds described above are dominated by the very intense $\mathrm{Eu}^{3+}$ luminescence. Therefore, in order to obtain a multi-emissive hetero-lanthanide-based coordination polymer with sizeable emission peaks intensities over the whole emission domain (visible and IR), relative contents of the emissive lanthanide ions must be adjusted. As a matter of example, $\left[\mathrm{Nd}_{0.03} \mathrm{Sm}_{0.14} \mathrm{Eu}_{0.03} \mathrm{La}_{1.8}(\mathrm{dcpa})_{3}\left(\mathrm{H}_{2} \mathrm{O}\right)\right]_{\infty}$ has been prepared (Figure S14 and Table S12). Excitation and emission spectra in both the visible and the IR domains at room-temperature have been recorded (Figures S32-S33 and Figure 11). Emission spectrum (Figure 11) shows a complex emission pattern with more than twenty sizeable emission peaks that can be attributed to $\mathrm{Nd}^{3+}, \mathrm{Sm}^{3+}$ or $\mathrm{Eu}^{3+}$ over all the studied spectral domain $(500 \mathrm{~nm}$ to $1250 \mathrm{~nm})$. Luminance, measured under UV irradiation $\left(\lambda_{\mathrm{exc}}=312 \mathrm{~nm} ; 0.75(2) \mathrm{mW} \cdot \mathrm{cm}^{-2}\right)$ is $12 \mathrm{Cd} . \mathrm{m}^{-2}$. To the best of our knowledge there is no example of lanthanide-based coordination polymer reported to date with such a complex and bright luminescent signature. Moreover this compound composition is not optimized and obviously there are plenty of other molecular alloys exhibiting such excellent properties that can be designed by application of the dilution effect strategy. This can be an asset as far as luminescent bar-codes would be targeted. 


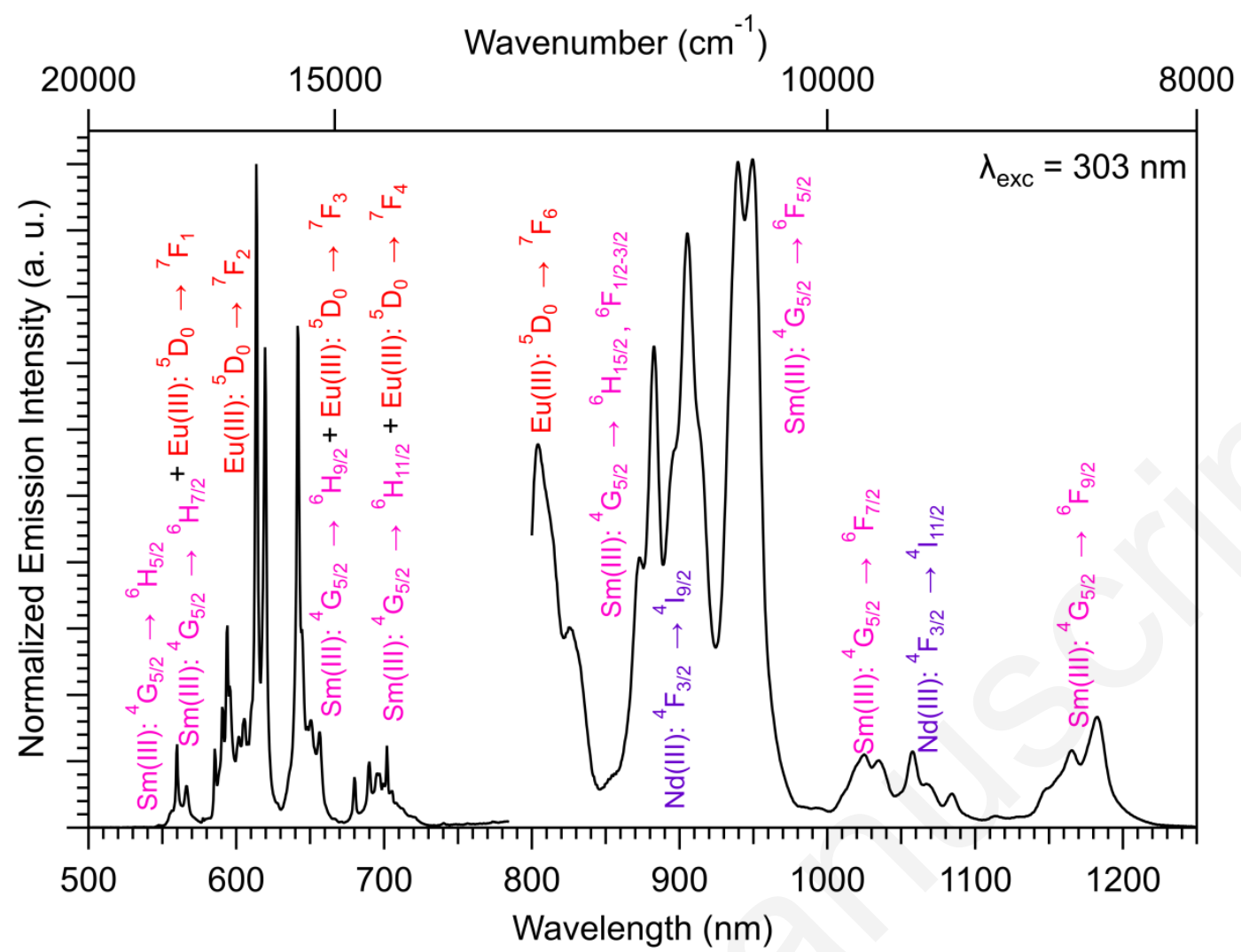

Figure 11. Room-temperature solid-state emission $\left(\lambda_{\text {exc }}=303 \mathrm{~nm}\right)$ spectra in both the visible and IR domains of $\left[\mathrm{Nd}_{0.03} \mathrm{Sm}_{0.14} \mathrm{Eu}_{0.03} \mathrm{La}_{1.8}(\mathrm{dcpa})_{3}\left(\mathrm{H}_{2} \mathrm{O}\right)\right]_{\infty} . \quad \tau_{\mathrm{Eu}}=0.93(1) \mathrm{ms}$ and $\tau_{\mathrm{Sm}}=0.39(1) \mathrm{ms}$.

\section{CONCLUSION AND OUTLOOK.}

Compounds that constitute this series of iso-structural light-lanthanides-based coordination polymers exhibit very intense and sometimes unprecedented luminescence. Indeed, as a matter of example, $\left[\mathrm{Sm}_{0.04} \mathrm{La}_{1.96}(\mathrm{dcpa})_{3}\left(\mathrm{H}_{2} \mathrm{O}\right)\right]_{\infty}$ presents one of the highest overall quantum yield measured so far for a $\mathrm{Sm}^{3+}$-based coordination compound $\left(\mathrm{Q}_{\mathrm{Sm}}^{\mathrm{Ligand}}=9.2 \%\right)$ and $\left[\mathrm{Nd}_{0.03} \mathrm{Sm}_{0.14} \mathrm{Eu}_{0.03} \mathrm{La}_{1.8}(\mathrm{dcpa})_{3}\left(\mathrm{H}_{2} \mathrm{O}\right)\right]_{\infty} \quad$ is one of the brightest multi-emissive lanthanide-coordination polymer reported to date $\left(12 \mathrm{Cd} \cdot \mathrm{m}^{-2}\right.$ under $0.75 \mathrm{~mW} \cdot \mathrm{cm}^{-2} \mathrm{UV}$ flux). When compared to other rare-earth coordination polymers the $\left[\operatorname{Ln}_{2-2 x} \operatorname{La}_{2 x}(\mathrm{dcpa})_{3}\left(\mathrm{H}_{2} \mathrm{O}\right)\right]_{\infty}$ family shows unexpected physico-chemical behavior: i) their dehydration is not reversible, a very rare feature with lanthanide-based coordination polymers probably due to high rigidity of the lanthanide surrounding ii) their luminescence is almost insensitive to such dehydration or to temperature changes, showing that few non-radiative 
de-excitations pathways are active in these samples. Overall, these experimental evidences could be due to a particularly rigid crystal packing that host very few efficient vibrators for non-radiative de-excitation and promote a mineral-like optical behavior with remarkable emission. These optical properties in conjunction with the green synthetic process of the coordination polymers (high yield synthesis in water at ambient temperature and pressure) and their good thermal stability (up to $400{ }^{\circ} \mathrm{C}$ ) make them attractive candidates as new luminescent taggants.

\section{SUPPORTING INFORMATION}

IR spectrum of $\left[\mathrm{Nd}_{2}(\mathrm{dcpa})_{3}\left(\mathrm{H}_{2} \mathrm{O}\right)\right]_{\infty}$; Experimental X-ray diffraction patterns of $\left[\operatorname{Ln}_{2}(\mathrm{dcpa})_{3}\left(\mathrm{H}_{2} \mathrm{O}\right)\right]_{\infty} \quad$ with $\mathrm{Ln}=\mathrm{La}-\mathrm{Gd} \quad$ except Pm, $\left[\mathrm{Eu}_{2-2 x} \mathrm{La}_{2 x}(\mathrm{dcpa})_{3}\left(\mathrm{H}_{2} \mathrm{O}\right)\right]_{\infty}$, $\left[\mathrm{Sm}_{2-2 x} \mathrm{La}_{2 x}(\mathrm{dcpa})_{3}\left(\mathrm{H}_{2} \mathrm{O}\right)\right]_{\infty}, \quad\left[\mathrm{Nd}_{2-2 x} \mathrm{La}_{2 x}(\mathrm{dcpa})_{3}\left(\mathrm{H}_{2} \mathrm{O}\right)\right]_{\infty}, \quad\left[\operatorname{Pr}_{2-2 x} \operatorname{La}_{2 x}(\mathrm{dcpa})_{3}\left(\mathrm{H}_{2} \mathrm{O}\right)\right]_{\infty}$, $\left[\operatorname{Pr}_{2-2 x} \mathrm{Eu}_{2 x}(\mathrm{dcpa})_{3}\left(\mathrm{H}_{2} \mathrm{O}\right)\right]_{\infty}, \quad\left[\mathrm{Nd}_{2-2 x} \mathrm{Eu}_{2 x}(\mathrm{dcpa})_{3}\left(\mathrm{H}_{2} \mathrm{O}\right)\right]_{\infty}, \quad\left[\mathrm{Sm}_{2-2 x} \mathrm{Eu}_{2 x}(\mathrm{dcpa})_{3}\left(\mathrm{H}_{2} \mathrm{O}\right)\right]_{\infty}$, $\left[\operatorname{Pr}_{0.2-0.2 x} \mathrm{Eu}_{0.2 x} \mathrm{La}_{1.8}(\mathrm{dcpa})_{3}\left(\mathrm{H}_{2} \mathrm{O}\right)\right]_{\infty}$, $\left[\mathrm{Nd}_{0.2-0.2 x} \mathrm{Eu}_{0.2 x} \operatorname{La}_{1.8}(\mathrm{dcpa})_{3}\left(\mathrm{H}_{2} \mathrm{O}\right)\right]_{\infty}$, $\left[\mathrm{Sm}_{0.2-0.2 x} \mathrm{Eu}_{0.2 x} \mathrm{La}_{1.8}(\mathrm{dcpa})_{3}\left(\mathrm{H}_{2} \mathrm{O}\right)\right]_{\infty}$ with $0 \leq x \leq 1$ and $\left[\mathrm{Nd}_{0.03} \mathrm{Sm}_{0.14} \mathrm{Eu}_{0.03} \mathrm{La}_{1.8}(\mathrm{dcpa})_{3}\left(\mathrm{H}_{2} \mathrm{O}\right)\right]_{\infty}$; Expected and experimental relative lanthanide contents for $\left[\mathrm{Eu}_{2-2 x} \mathrm{La}_{2 x}(\mathrm{dcpa})_{3}\left(\mathrm{H}_{2} \mathrm{O}\right)\right]_{\infty}$, $\left[\mathrm{Sm}_{2-2 x} \mathrm{La}_{2 x}(\mathrm{dcpa})_{3}\left(\mathrm{H}_{2} \mathrm{O}\right)\right]_{\infty}, \quad\left[\mathrm{Nd}_{2-2 x} \mathrm{La}_{2 x}(\mathrm{dcpa})_{3}\left(\mathrm{H}_{2} \mathrm{O}\right)\right]_{\infty}, \quad\left[\operatorname{Pr}_{2-2 x} \mathrm{La}_{2 x}(\mathrm{dcpa})_{3}\left(\mathrm{H}_{2} \mathrm{O}\right)\right]_{\infty}$, $\left[\operatorname{Pr}_{2-2 x} \mathrm{Eu}_{2 x}(\mathrm{dcpa})_{3}\left(\mathrm{H}_{2} \mathrm{O}\right)\right]_{\infty}, \quad\left[\mathrm{Nd}_{2-2 x} \mathrm{Eu}_{2 x}(\mathrm{dcpa})_{3}\left(\mathrm{H}_{2} \mathrm{O}\right)\right]_{\infty}, \quad\left[\mathrm{Sm}_{2-2 x} \mathrm{Eu}_{2 x}(\mathrm{dcpa})_{3}\left(\mathrm{H}_{2} \mathrm{O}\right)\right]_{\infty}$, $\left[\operatorname{Pr}_{0.2-0.2 x} \mathrm{Eu}_{0.2 x} \mathrm{La} 1.8(\mathrm{dcpa})_{3}\left(\mathrm{H}_{2} \mathrm{O}\right)\right]_{\infty}$, $\left[\mathrm{Nd}_{0.2-0.2 x} \mathrm{Eu}_{0.2 x} \mathrm{La}_{1.8}(\mathrm{dcpa})_{3}\left(\mathrm{H}_{2} \mathrm{O}\right)\right]_{\infty}$, $\left[\mathrm{Sm}_{0.2-0.2 x} \mathrm{Eu}_{0.2 x} \mathrm{La}_{1.8}(\mathrm{dcpa})_{3}\left(\mathrm{H}_{2} \mathrm{O}\right)\right]_{\infty}$ with $0 \leq x \leq 1$ and $\left[\mathrm{Nd}_{0.03} \mathrm{Sm}_{0.14} \mathrm{Eu}_{0.03} \mathrm{La}_{1.8}(\mathrm{dcpa})_{3}\left(\mathrm{H}_{2} \mathrm{O}\right)\right]_{\infty}$; Experimental, calculated, and difference X-ray powder pattern of $\left[\mathrm{Eu}_{2}(\mathrm{dcpa})_{3}\left(\mathrm{H}_{2} \mathrm{O}\right)\right]_{\infty}$ refined in the $P 2{ }_{1} / c$ space group by the Le Bail method; Room-temperature solid-state UV-vis absorption spectrum of $\left[\mathrm{La}_{2}(\mathrm{dcpa})_{3}\left(\mathrm{H}_{2} \mathrm{O}\right)\right]_{\infty}$; Solid-state excitation and emission spectra of $\left[\mathrm{La}_{2}(\mathrm{dcpa})_{3}\left(\mathrm{H}_{2} \mathrm{O}\right)\right]_{\infty}$ recorded at $77 \mathrm{~K}$; Room-temperature solid-state excitation and emission spectra of $\left[\mathrm{Eu}_{2}(\mathrm{dcpa})_{3}\left(\mathrm{H}_{2} \mathrm{O}\right)\right]_{\infty}$ and $\left[\mathrm{Eu}_{2}(\mathrm{dcpa})_{3}\right]_{\infty} ;$ Luminance $v s \quad x$ of $\left[\mathrm{Eu}_{2-2 \mathrm{x}} \mathrm{La}_{2 \mathrm{x}}(\mathrm{dcpa})_{3}\left(\mathrm{H}_{2} \mathrm{O}\right)\right]_{\infty}$ and $\left[\mathrm{Sm}_{2-2 \mathrm{x}} \mathrm{La}_{2 \mathrm{x}}(\mathrm{dcpa})_{3}\left(\mathrm{H}_{2} \mathrm{O}\right)\right]_{\infty}$ with $0 \leq x \leq 1$; Integrated area of the emission peaks of $\left[\operatorname{Pr}_{2-2 x} \mathrm{La}_{2 x}(\mathrm{dcpa})_{3}\left(\mathrm{H}_{2} \mathrm{O}\right)\right]_{\infty}, \quad\left[\mathrm{Nd}_{2-2 x} \mathrm{La}_{2 x}(\mathrm{dcpa})_{3}\left(\mathrm{H}_{2} \mathrm{O}\right)\right]_{\infty}$, $\left[\mathrm{Sm}_{2-2 x} \mathrm{La}_{2 x}(\mathrm{dcpa})_{3}\left(\mathrm{H}_{2} \mathrm{O}\right)\right]_{\infty}$ and $\left[\mathrm{Eu}_{2}-2 x \mathrm{La}_{2 x}(\mathrm{dcpa})_{3}\left(\mathrm{H}_{2} \mathrm{O}\right)\right]_{\infty}$ with $0 \leq x \leq 1$ series; Visible emission spectra $v s$ temperature of $\left[\operatorname{Pr}_{2}(\mathrm{dcpa})_{3}\left(\mathrm{H}_{2} \mathrm{O}\right)\right]_{\infty}$ and $\left[\operatorname{Pr}_{0.2} \mathrm{La}_{1.8}(\mathrm{dcpa})_{3}\left(\mathrm{H}_{2} \mathrm{O}\right)\right]_{\infty}$; Infrared emission spectra $v s$ temperature of $\left[\mathrm{Nd}_{2}(\mathrm{dcpa})_{3}\left(\mathrm{H}_{2} \mathrm{O}\right)\right]_{\infty}$ and $\left[\mathrm{Nd}_{0.2} \mathrm{La}_{1.8}(\mathrm{dcpa})_{3}\left(\mathrm{H}_{2} \mathrm{O}\right)\right]_{\infty}$; Visible emission spectra vs temperature of $\left[\mathrm{Sm}_{2}(\mathrm{dcpa})_{3}\left(\mathrm{H}_{2} \mathrm{O}\right)\right]_{\infty}$ and $\left[\mathrm{Sm}_{0.2} \mathrm{La}_{1.8}(\mathrm{dcpa})_{3}\left(\mathrm{H}_{2} \mathrm{O}\right)\right]_{\infty}$; Infrared emission spectra $v s$ temperature of $\left[\mathrm{Eu}_{2}(\mathrm{dcpa})_{3}\left(\mathrm{H}_{2} \mathrm{O}\right)\right]_{\infty}$ and $\left[\mathrm{Eu}_{0.2} \mathrm{La}_{1.8}(\mathrm{dcpa})_{3}\left(\mathrm{H}_{2} \mathrm{O}\right)\right]_{\infty} ;$ Integrated emission intensities vs temperature of $\left[\operatorname{Pr}_{2}(\mathrm{dcpa})_{3}\left(\mathrm{H}_{2} \mathrm{O}\right)\right]_{\infty} \quad$ and $\quad\left[\mathrm{Pr}_{0.2} \mathrm{La}_{1.8}(\mathrm{dcpa})_{3}\left(\mathrm{H}_{2} \mathrm{O}\right)\right]_{\infty}, \quad\left[\mathrm{Nd}_{2}(\mathrm{dcpa})_{3}\left(\mathrm{H}_{2} \mathrm{O}\right)\right]_{\infty} \quad$ and $\left[\mathrm{Nd}_{0.2} \mathrm{La}_{1.8}(\mathrm{dcpa})_{3}\left(\mathrm{H}_{2} \mathrm{O}\right)\right]_{\infty}, \quad\left[\mathrm{Sm}_{2}(\mathrm{dcpa})_{3}\left(\mathrm{H}_{2} \mathrm{O}\right)\right]_{\infty} \quad$ and $\quad\left[\mathrm{Sm}_{0.2} \mathrm{La}_{1.8}(\mathrm{dcpa})_{3}\left(\mathrm{H}_{2} \mathrm{O}\right)\right]_{\infty}$, $\left[\mathrm{Eu}_{2}(\mathrm{dcpa})_{3}\left(\mathrm{H}_{2} \mathrm{O}\right)\right]_{\infty}$ and $\left[\mathrm{Eu}_{0.2} \mathrm{La}_{1.8}(\mathrm{dcpa})_{3}\left(\mathrm{H}_{2} \mathrm{O}\right)\right]_{\infty} ;$ Room-temperature solid-state emission spectra in the visible domain and in the IR domain of $\left[\mathrm{Nd}_{2-2 x} \mathrm{Eu}_{2 x}(\mathrm{dcpa})_{3}\left(\mathrm{H}_{2} \mathrm{O}\right)\right]_{\infty}$, 
$\left[\operatorname{Pr}_{2-2 x} \operatorname{Eu}_{2 x}(\mathrm{dcpa})_{3}\left(\mathrm{H}_{2} \mathrm{O}\right)\right]_{\infty}, \quad\left[\mathrm{Sm}_{2-2 x} \mathrm{Eu}_{2 x}(\mathrm{dcpa})_{3}\left(\mathrm{H}_{2} \mathrm{O}\right)\right]_{\infty}, \quad\left[\operatorname{Pr}_{0.2-0.2 x} \mathrm{Eu}_{0.2 x} \mathrm{Laa}_{1.8}(\mathrm{dcpa})_{3}\left(\mathrm{H}_{2} \mathrm{O}\right)\right]_{\infty}$, $\left[\mathrm{Nd}_{0.2-0.2 \times} \mathrm{Eu}_{0.2 \times} \mathrm{La}_{1.8}(\mathrm{dcpa})_{3}\left(\mathrm{H}_{2} \mathrm{O}\right)\right]_{\infty}$ and $\left[\mathrm{Sm}_{0.2-0.2 \times} \mathrm{Eu}_{0.2 \times} \mathrm{Laa}_{1.8}(\mathrm{dcpa})_{3}\left(\mathrm{H}_{2} \mathrm{O}\right)\right]_{\infty}$ with $x=0,0.25$, $0.5,0.75$ and 1; Room-temperature solid-state excitation and emission spectra in the visible and the IR domains of $\left[\mathrm{Nd}_{0.03} \mathrm{Sm}_{0.14} \mathrm{Eu}_{0.03} \mathrm{La}_{1.8}(\mathrm{dcpa})_{3}\left(\mathrm{H}_{2} \mathrm{O}\right)\right]_{\infty}$. 


\section{REFERENCES}

1. Berg, E. W.; Alam, A., Studies on coordination polymers. Part I : Coordination polymers of 8,8'-dihydroxy-5,5'-biquinolyl. Anal. Chim. Acta 1962, 27, 454-459.

2. Bünzli, J. C. G., Rising stars in science and technology : Luminescent lanthanide materials. Eur. J. Inorg. Chem. 2017, 5058-5063.

3. Bünzli, J. C. G.; Eliseeva, S. V., Intriguing aspect of lanthanide luminescence. Chem. Sci. 2013, 4, 1039-1049.

4. Bünzli, J. C. G.; Piguet, C., Taking advantage of luminescent ions. Chem. Soc. Rev. 2005, 34, 1048-1077.

5. Cui, Y.; Zhang, J.; He, H.; Qian, G., Photonic functional metal-organic frameworks. Chem. Soc. Rev. 2018, 47, 5740-5785.

6. Cui, Y.; Li, B.; He, H.; Zhou, W.; Chen, B.; Qian, G., Metal-organic frameworks as platforms for functionnal materials. Accounts Chem. Res. 2016, 49, 483-493.

7. Li, B.; Wen, H.-M.; Cui, Y.; Qian, G.; Chen, B., Multifunctionnal lanthanide coordination polymers. Prog. Polym. Sci. 2015, 48, 40-84.

8. Cui, Y.; Yue, Y.; Qian, G.; Chen, B., Luminescent Functional Metal-Organic Frameworks. Chem. Rev. 2012, 1126-1162.

9. Binnemans, K., Lanthanide based luminescent hybrid materials. Chem. Rev. 2009, 109, 42834374.

10. Rocha, J.; Brites, D. S. C.; Carlos, L. D., Lanthanide organic framework luminescent thermometers. Chem. - Eur. J. 2016, 22, 14782-14795.

11. Brites, D. S. C.; Millan, A.; Carlos, L. D., Lanthanides in Luminescent Thermometry. In Handbook on the Physics and Chemistry of Rare Earths, Gschneidner, K. A.; Bünzli, J. C. G.; Pecharsky, V. K., Eds. Elsevier: 2016; Vol. 49, p 339-427.

12. Eliseeva, S. V.; Bünzli, J. C. G., Lanthanide luminescence for functionnal materials and biosciences. Chem. Soc. Rev. 2010, 39, 189-227.

13. Bünzli, J.-C. G., Lanthanide luminescence for biomedical analyses and imaging. Chem. Rev. 2010, 111, 2729-2755.

14. Ning, Y.; Zhu, M.; Zhang, J.-L., Near-infrared (NIR) lanthanide molecular probes for bioimaging and biosensing. Coord. Chem. Rev. 2019, 213028.

15. He, J.; Xu, J.; Yin, J.; Li, N.; Bu, X.-H., Recent advances in luminescent metal-organic frameworks for chemical sensors. Science China Materials 2019, 62, 1655-1678.

16. Wang, Z.; Yang, Y.; Cui, Y.; Wang, Z.; Qian, G., Color-tunable and white-light emitting lanthanide complexes based on $\left(\mathrm{Ce}_{\mathrm{x}} \mathrm{Eu}_{\mathrm{y}} \mathrm{TB}_{1-\mathrm{x}-\mathrm{y}}\right)_{2}(\mathrm{BDC})_{3}\left(\mathrm{H}_{2} \mathrm{O}\right)_{4}$. J. Alloys Compd. 2012, 510, L5-L8.

17. Andres, J.; Hersch, R. D.; Moser, J. E.; Chauvin, A. S., A new counterfeiting feature relying on invisible luminescent full color images printed with lanthanide-based Inks. Adv. Func. Mater. 2014, 24, 5029-5036.

18. Guillou, O.; Daiguebonne, C.; Calvez, G.; Bernot, K., A long journey in lanthanide chemistry : from fundamental crystallogenesis studies to commercial anti-counterfeiting taggants. Accounts Chem. Res. 2016, 49, 844-856.

19. White, K. A.; Chengelis, D. A.; Gogick, K. A.; Stehman, J.; Rosi, N. L.; Petoud, S., Near infra-red luminescent lanthanide MOF barcodes. J. Am. Chem. Soc. 2009, 131, 18069-18071.

20. Badiane, A. M.; Freslon, S.; Daiguebonne, C.; Suffren, Y.; Bernot, K.; Calvez, G.; Costuas, K.; Camara, M.; Guillou, O., Lanthanide based coordination polymers with a 4,5-dichlorophthalateligand exhibiting highly tunable luminescence : Toward luminescent bar codes. Inorg. Chem. 2018, 57, 33993410.

21. Cui, Y.; Zhang, J.; Chen, B.; Qian, G., Lanthanide Metal-Organic Frameworks for Luminescent Applications. Handbook on the Physics and Chemistry of Rare Earths 2016, 50, 243-268.

22. Piguet, C.; Bünzli, J. C. G.; Bernardinelli, G.; Hopfgatner, G.; Williams, A. F., Self-assembly and photophysical properties of lanthanide dinuclear triple-helical complexes. J. Am. Chem. Soc. 1993, $115,8197-8206$. 
23. Bünzli, J. C. G., On the design of highly luminescent lanthanide complexes. Coord. Chem. Rev. 2015, 293-294, 19-47.

24. Eliseeva, S. V.; Pleshkov, D. N.; Lyssenko, K. A.; Lepnev, L. S.; Bünzli, J. C. G.; Kuzmina, N. P., Highly luminescent and triboluminescent coordination polymers assembled from Lanthanide betadiketonate and aromatic bidentate O-donor ligands. Inorg. Chem. 2010, 49, 9300-9311.

25. Freslon, S.; Luo, Y.; Calvez, G.; Daiguebonne, C.; Guillou, O.; Bernot, K.; Michel, V.; Fan, X., Influence of photo-induced electron transfer on lanthanide-based coordination polymers luminescence : A comparison between two pseudo-isoreticular molecular networks. Inorg. Chem. 2014, 53, 1217-1228.

26. Biju, S.; Eom, Y. K.; Bünzli, J. C. G.; Kim, H. K., new tetrakis b-diketone ligand for NIR emitting LnIII ions: luminescent doped PMMA films and flexible resins for advanced photonic applications. J. Mater. Chem. C 2013, 1, 6935-6944.

27. Calvez, G.; Le Natur, F.; Daiguebonne, C.; Bernot, K.; Suffren, Y.; Guillou, O., Lanthanide -based hexanuclear complexes and their use as molecular precursors. Coord. Chem. Rev. 2017, 340, 134-153. 28. Le Natur, F.; Calvez, G.; Daiguebonne, C.; Guillou, O.; Bernot, K.; Ledoux, J.; Le Polles, L.; Roiland, C., Coordination polymers based on hexanuclear rare earth complexes: Toward independant luminescence brightness and color emission. Inorg. Chem. 2013, 52, 6720-6730.

29. Calvez, G.; Daiguebonne, C.; Guillou, O., Unprecedented lanthanide containing coordination polymers constructed from hexanuclear molecular building blocks: $\left\{\left[\mathrm{Ln}_{6} \mathrm{O}(\mathrm{OH})_{8}\right]\left(\mathrm{NO}_{3}\right)_{2}(\mathrm{bdc})(\mathrm{Hbdc})_{2}, 2 \mathrm{NO}_{3}, \mathrm{H}_{2} \text { bdc }\right\}_{n}$. Inorg. Chem. 2011, 50, 2851-2858.

30. Haquin, V.; Etienne, M.; Daiguebonne, C.; Freslon, S.; Calvez, G.; Bernot, K.; Le Polles, L.; Ashbrook, S. E.; Mitchell, M. R.; Bünzli, J. C. G.; Guillou, O., Color and brightness tuning in heteronuclear lanthanide teraphthalate coordination polymers. Eur. J. Inorg. Chem. 2013, 3464-3476.

31. Zhou, D.; Huang, C.; Wang, K.; Xu, G., Synthesis, characterization, crystal structure and luminescent property studies on a novel heteronuclear lanthanide complex $\left\{\mathrm{H}\left[\mathrm{EuLa}_{2}(\mathrm{DPA})_{5} .8 \mathrm{H}_{2} \mathrm{O}\right\}_{\mathrm{n}}\right.$ ( $\mathrm{H}_{2} \mathrm{PDA}=$ pyridine-2,6-dicarboxylique acid). Polyhedron 1994, 13, 987-991.

32. Dechambenoit, P.; Ferlay, S.; Kyritsakas, N.; Hosseini, M. W., Playing with isostructurality: from tectons to molecular alloys and composite crystals. Chem. Comm. 2009, 1559-1561.

33. Dang, S.; Zhang, J. H.; Sun, Z. M., Tunable emission based on lanthanide(III) metal organic frameworks : an alternative approach to white light. J. Mater. Chem. 2012, 22, 8868-8873.

34. Zhao, X. J.; Yang, J. H.; Liu, Y.; Gao, P. F.; Li, Y. F., Metal-organic coordination polymers of Tb2$\mathrm{xEux}(\mathrm{bdc}) 3(\mathrm{H} 2 \mathrm{O}) \mathrm{n}$ with tunable fluorescence and smart response toward aldehydes. RSC Advances 2014, 4, 2573-2576.

35. Li, X.-Y.; Shi, W.-J.; Wang, X.-Q.; Ma, L.-N.; Hou, L.; Wang, Y.-Y., Luminescence modulation, white light emission and energy transfer in a family of lanthanide Metal-Organic Frameworks based on a planar $\pi$-conjugated ligand. Cryst. Growth Des. 2017, 17, 4217-4224.

36. Zhou, X.; Wang, H.; Jiang, S.; Xiang, G.; Tang, X.; Luo, X.; Li, L.; Zhou, X., Multifunctional luminescent material $\mathrm{Eu}(\mathrm{III})$ and $\mathrm{Tb}$ (III) complexes with pyridine-3,5-dicarboxylic acid linker; Crystal structures, tunable emission, Energy transfer and temperature sensing. Inorg. Chem. 2019, 58, 37803788.

37. Abdallah, A.; Freslon, S.; Fan, X.; Rojo, A.; Daiguebonne, C.; Suffren, Y.; Bernot, K.; Calvez, G.; Roisnel, T.; Guillou, O., Lanthanide based coordination polymers with 1,4 carboxyphenylboronic ligand: multi emissive compounds for multi sensitive luminescent thermometric probes. Inorg. Chem. 2019, 58, 462-475.

38. Badiane, I.; Freslon, S.; Suffren, Y.; Daiguebonne, C.; Calvez, G.; Bernot, K.; Camara, M.; Guillou, O., High britness and easy color modulation in lanthanide-based coordination polymers with 5-methoxyisophthalate as ligand: Toward emission colors additive strategy. Cryst. Growth Des. 2017, 17, 1224-1234.

39. Freslon, S.; Luo, Y.; Daiguebonne, C.; Calvez, G.; Bernot, K.; Guillou, O., Brightness an d color tuning in a series of lanthanide-based coordination polymers with benzene 1,2,4,5-tetracarboxylic acid as ligand. Inorg. Chem. 2016, 55, 794-802. 
40. Luo, Y.; Zheng, Y.; Calvez, G.; Freslon, S.; Bernot, K.; Daiguebonne, C.; Roisnel, T.; Guillou, O., Synthesis, crystal structure and luminescent properties of new lanthanide-containing coordination polymers Involving 4,4'-oxy-bis-benzoate as Ligand. CrystEngComm. 2013, 15, 706-720.

41. Tang, Q.; Liu, S.; Liu, Y.; He, D.; Miao, J.; Ji, Y.; Zheng, Z., Color tuning and white light emission via in situ doping of luminescent lanthanide metal-organic frameworks. Inorg. Chem. 2014, 53, 289293.

42. Karraker, D. G., Coordination of trivalent lanthanide ions. J. Chem. Educ. 1970, 47, 424-430.

43. Bünzli, J. C. G.; Eliseeva, S. V., Basics of lanthanide photophysics. In Lanthanide Luminescence, Hänninen, P.; Härmä, H., Eds. Springer Berlin Heidelberg: 2010; Vol. 7, p 1-45.

44. Anastas, P. T.; Warner, J. C., Green Chemistry: Theory and Practice. Oxford University Press Inc.: New-York, 2000.

45. Weissman, S. I., Intramolecular energy transfer - The fluorescence of complexes of europium. J. Chem Phys 1942, 10, 214-217.

46. He, H.; Chen, S.-H.; Zhang, D.-Y.; Hao, R.; Zhang, C.; Yang, E.-C.; Zhao, X.-J., A micrometersized europium(III)-organic framework for selective sensing of the $\mathrm{Cr}_{20}{ }^{2-}$ anion and picric acid in water systems. Dalton Trans. 2017, 46, 13502-13509.

47. Qiao, Y.-H.; Chen, S.-H.; Xu, S.; Yang, E. C.; Zhao, X.-J., 4,5-dichlorophthalate-extended lanthanide coordination polymers with layer and ribbon motifs: synthesis, structure, and luminescence. Z. Anorg. Allg. Chem. 2018, 644, 1108-114.

48. Desreux, J. F., In Lanthanide Probes in Life, Chemical and Earth Sciences, Choppin, G. R.; Bünzli, J. C. G., Eds. Elsevier: Amsterdam, 1989; Vol. Elsevier, p 43.

49. Fan, X.; Freslon, S.; Daiguebonne, C.; Le Polles, L.; Calvez, G.; Bernot, K.; Guillou, O., A family of lanthanide based coordination polymers with boronic acid as ligand. Inorg. Chem. 2015, 54, 55345546.

50. Fan, X.; Freslon, S.; Daiguebonne, C.; Calvez, G.; Le Polles, L.; Bernot, K.; Guillou, O., Heteronuclear lanthanide-based coordination polymers exhibiting tunable multiple emission spectra. J. Mater. Chem. C 2014, 5510-5525.

51. Roisnel, T.; Rodriguez-Carjaval, J., A Window Tool for Powder Diffraction Patterns Analysis. J. Mater. Sci. Forum 2001, 378, 118-123.

52. Kraus, W.; Nolze, G., POWDER CELL - A program for the representation and manipulation of crystal structures and calculation of the resulting X-ray powder patterns. J. Appl. Crystallogr. 1996, 29, 301-303.

53. Rodriguez-Carvajal, Recent advances in magnetic structure determination by neutron powder diffraction. Physica B 1993, 192, 55-59.

54. Le Bail, A.; Duroy, H.; Fourquet, J. L., Ab-initio structure determination ofLiSbWO $0_{8}$ by x-ray powder diffraction. Material Research Bulletin 1988, 23, 447-452.

55. CIE, International Commission on Illumination - Technical report. CIE: 1995; Vol. 13-3, p 16.

56. Wyszecki, G., Colorimetry. In Handbook of Optics, Driscoll, W. G.; Vaughan, W., Eds. Mac Graw-Hill Book Company: New-York, 1978, p 1-15.

57. Daiguebonne, C.; Guillou, O.; Gérault, Y.; Boubekeur, K., Structural diversity in lanthanide complexes chemistry : the Ln 3+ - TMA 3- - H 2 O system. Recent Research Development in Inorganic Chemistry 2000, 2, 165-183.

58. Steemers, F. J.; Verboom, W.; Reinhoudt, D. N.; Van der Tol, E. B.; Verhoeven, J. W., New sensitizer-modified calix[4]arenes enabling Near-UV Excitation of complexed luminescent lanthanide ions. J. Am. Chem. Soc. 1995, 117, 9408-9414.

59. Carnall, W. T.; Fields, P. R.; Rajnak, K., Electronic energy levels of the trivalent lanthanide ions. IV. Eu ${ }^{3+}$. J. Chem. Phys. 1968, 49, 4450-4455.

60. Latva, M.; Takalo, H.; Mukkala, V.-M.; Matachescu, C.; Rodriguez-Ubis, J. C.; Kankare, J., Correlation between the lowest triplet state energy level of the ligand and lanthanide luminescence quantum yields. J. Lumin. 1997, 75, 149-169. 
61. Comby, S.; Bünzli, J. C. G.; Gschneider, K. A.; Pecharsky, V. K., Lanthanide Near-Infrared Luminescence in Molecular Probes and Devices. In Handbook on the Physics and Chemistry of Rare Earths, Elsevier: Amsterdam, 2007; Vol. 37, p 1-353.

62. Werts, M. H. V.; Jukes, R. T. F.; Verhoeven, J. W., The emission spectrum and the radiative lifetime of Eu3+ in lanthanide luminescent complexes. Phys Chem Chem Phys 2002, 4, 1542-1548.

63. Chauvin, A. S.; Gumy, F.; Imbert, D.; Bünzli, J. C. G., Europium and terbium tris(dipicolinate) as secondary standards for quantum yield determination. Spectrosc Lett 2004, 37, 512-532.

64. Kerbellec, N.; Kustaryono, D.; Haquin, V.; Etienne, M.; Daiguebonne, C.; Guillou, O., An Unprecedented Family of Lanthanide-Containing Coordination Polymers with Highly Tunable Emission Properties. Inorg. Chem. 2009, 48, 2837-2843.

65. Carnall, W. T.; Fields, P. R.; Rajnak, K., Spectral intensities of the trivalent lanthanides and actinides in solution. II. $\mathrm{Pm}^{3+}, \mathrm{Sm}^{3+}, \mathrm{Eu}^{3+}, \mathrm{Gd}^{3+}, \mathrm{Tb}^{3+}, \mathrm{Dy}^{3+}$ and $\mathrm{Ho}^{3+}$. J. Chem. Phys. 1968, 49, 44124423.

66. Carnall, W. T.; Fields, P. R.; Wybourne, B. G., Spectral intensities of the trivalent lanthanides and actinides in solution. I. $\mathrm{Pr}^{3+}, \mathrm{Nd}^{3+}, \mathrm{Er}^{3+}, \mathrm{Tm}^{3+}$ and $\mathrm{Yb}^{3+}$. J. Chem. Phys. 1965, 42, 3797-3806.

67. Chorazy, S.; Arczynski, M.; Nakabayashi, K.; Sieklucka, B.; Ohkoshi, S.-I., Visible to NearInfrared emission from LnIII(Bis-oxazoline)-[MoV(CN)8] ( $\mathrm{Ln}=\mathrm{Ce}-\mathrm{Yb}$ ) magnetic coordination polymers showing unusual lanthanide-dependent sliding of cyanido-bridged layers. Inorg. Chem. 2015, 54, 4724-4736.

68. Decadt, R.; Van Hecke, K.; Depla, D.; Leus, K.; Weidenberg, D.; Van Driessche, I.; Van der Voort, P.; Van Deun, R., Synthesis, Crystal structures and luminescence properties of carboxylate based rare-earth coordination polymers. Inorg. Chem. 2012, 51, 11623-11634.

69. Xu, Y.-Y.; Chen, P.; Gao, T.; Li, H.-F.; Yan, P.-F., White-light emission based on a single component $\mathrm{Sm}$ (III) complex and enhanced optical properties by doping methods. CrystEngComm. 2019, 21, 964-970.

70. Sun, M.-L.; Zhang, J.; Lin, Q.-P.; Xiu, P.-X.; Yao, Y.-G., Multifunctional homochiral lanthanide camphorates with mixed achiral terephthalate ligands. Inorg. Chem. 2010, 49, 9257-9264.

71. Wei, X.-H.; Yang, L.-Y.; Liao, S.-Y.; Zhang, M.; Tian, J.-T.; Du, P.-Y.; Gu, W.; Liu, X., A series of rare earth complexes with novel non-interpenetrating 3D networks: synthesis, structures, magnetic and optical properties. Dalton Trans. 2014, 43, 5793-5800.

72. Han, Y.; Yan, P.; Sun, J.; An, G.; Yao, X.; Li, Y.; Li, G., Luminescence and white-light emitting luminescent sensor of tetrafluoroterephthalatelanthanide metal-organic frameworks. Dalton Trans. 2017, 46, 4642-4653.

73. Xiao, Y.; Wang, S.-H.; Zheng, F.-K.; Wu, M.-F.; Xu, J.; Liu, Z.-F.; Chen, J. E.; Li, R.-W.; Guo, G.-C., Excitation wavelength-induced color tunable and white-light emissions in lanthanide(III) coordination polymers constructed by an environment-dependent luminescent tetrazolate-dicarboxylate ligand. CrystEngComm. 2016, 18, 721-727.

74. Zhang, Y.-H.; Li, X.; Song, S., White light emission based on a single component Sm(III) framework and a two component $\mathrm{Eu}(\mathrm{III})$-doped $\mathrm{Gd}$ (III) framework constructed from 2,20diphenyldicarboxylate and $1 \mathrm{H}$-imidazo[4,5-f $][1,10]$-phenanthroline. Chem. Comm. 2013, 49, 1039710399.

75. Choi, C.-L.; Yen, Y.-F.; Sung, H. H.-Y.; Siu, A. W.-H.; Jayarathne, S. T.; Wong, K. S.; Williams, I. D., Quantifying enhanced photoluminescence in mixed-lanthanide carboxylate polymers: sensitization versus reduction of self-quenching. J. Mater. Chem. 2011, 21, 8547-8549. 


\section{TABLE OF CONTENT.}

Molecular alloys of light-lanthanides-based coordination polymers with very high lanthanum concentrations present highly tunable and very intense luminescence in the visible and IR domains.

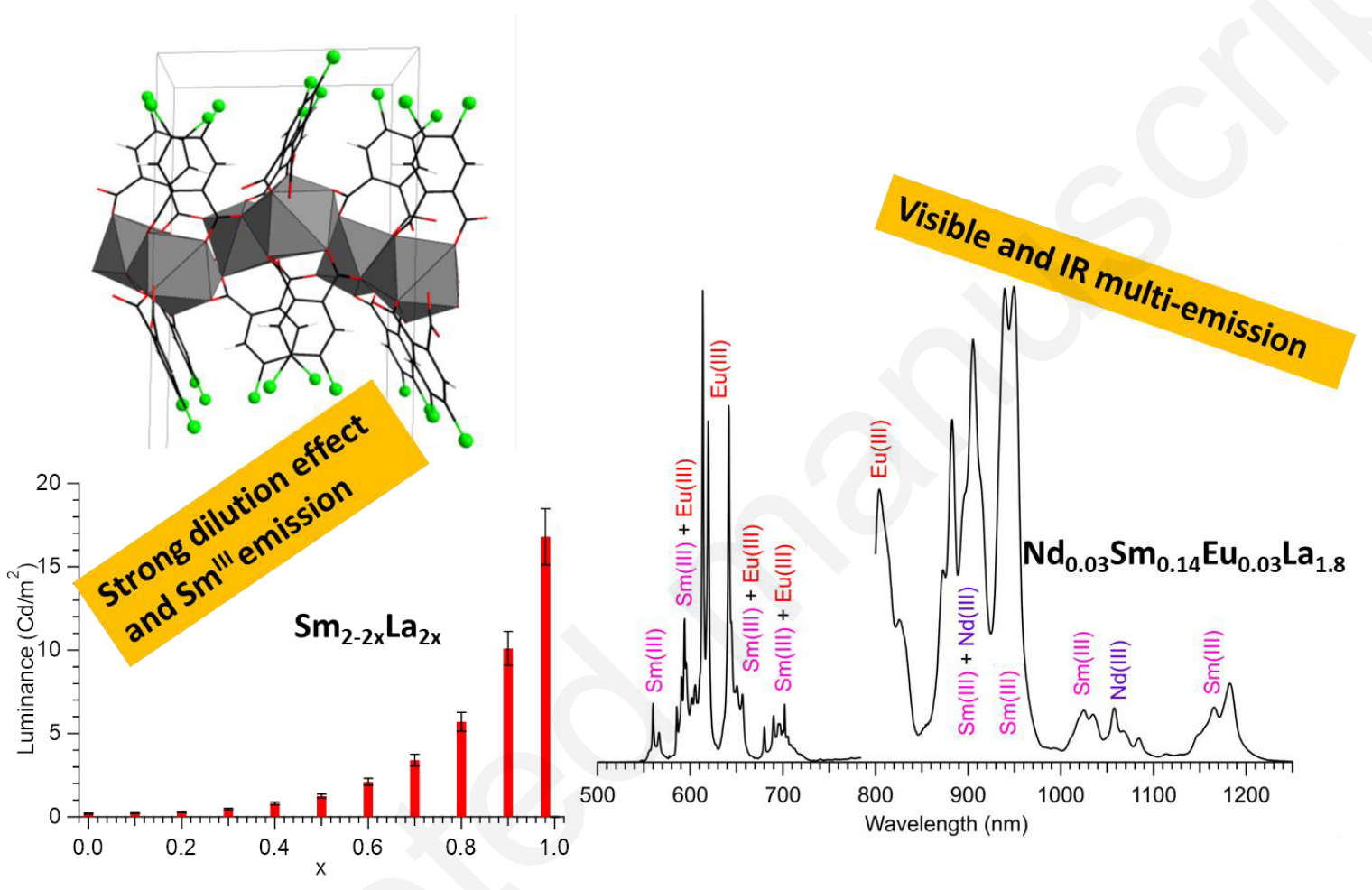

